\title{
Improving energy efficiency in manufacturing using peer benchmarking to influence machine design innovation
}

\author{
Phil Sheppard ${ }^{1}\left[\right.$. Shahin Rahimifard ${ }^{1}$ (1)
}

Received: 11 January 2019 / Accepted: 23 April 2019 / Published online: 8 May 2019

(c) The Author(s) 2019

\begin{abstract}
Energy efficiency in manufacturing is important for overall sustainability of society. This paper combines three observations to improve an overlooked part of the energy efficiency support infrastructure in food and drink manufacturing: innovation capability. First, variations in machine and process design produce significant differences in energy efficiency; second, these differences are not widely known or valued because comparable machine energy data are not gathered for the vast majority of products, so machine and process design is under-used as a route to efficiency improvement; third, peer benchmarking has proved to be an effective tool for stimulating change in other contexts, but has not been used at machine level in manufacturing. This paper describes and makes the case for a self-sustaining system in which machines would be validly compared on energy consumption and peer benchmarking would stimulate innovation in machine and process design for food manufacturing. The system, to be tested in a feasibility study, would benefit both food manufacturers and stakeholders. It would avoid dependence on public funding and enable stakeholders to provide value from the data. The paper contains the academic underpinning for the system and sets out an effective means of using it to achieve practical change.
\end{abstract}

Electronic supplementary material The online version of this article (https://doi.org/10.1007/s10098-019-01701-4) contains supplementary material, which is available to authorized users.

Phil Sheppard

p.sheppard@lboro.ac.uk

Shahin Rahimifard

s.rahimifard@lboro.ac.uk

1 Centre for Sustainable Manufacturing and Recycling

Technologies (SMART), Loughborough University,

Loughborough, Leicestershire LE11 3TU, UK 


\section{Graphical abstract}

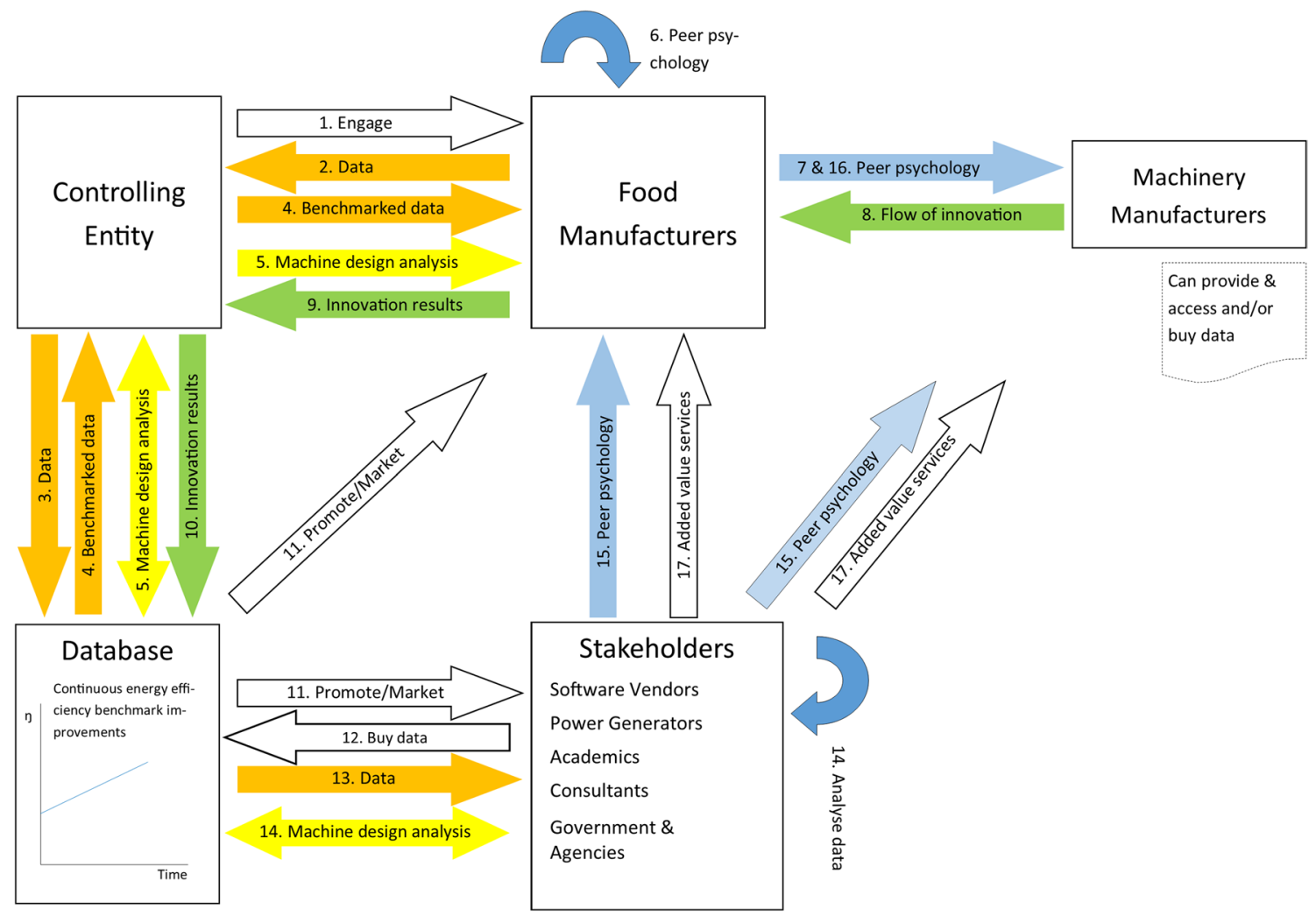

Keywords Energy efficiency $\cdot$ Support infrastructure $\cdot$ Manufacturing $\cdot$ Food and drink $\cdot$ Peer benchmarking $\cdot$ Innovation capability $\cdot$ Big Data $\cdot$ Machine design

\section{Introduction}

Driven by the political drivers of global warming, energy security and energy affordability, energy efficiency in food and drink manufacturing (shortened to 'food manufacturing' throughout this paper) and other industrial sectors in many countries has received significant attention in industry and government reports, in addition to the academic literature. Food manufacturing accounts for around $4.1 \%$ of industrial sector energy consumption in the developed (OECD) economies and 2.4\% in non-OECD countries (Energy Information Administration 2016 and personal communication, June 2017). In the UK, food manufacturing accounts for $16 \%$ of energy consumption in manufacturing, the fourth largest manufacturing sub-sector (Department for Business, Energy \& Industrial Strategy 2018).

Manufacturing is of course only one stage of the full food supply chain, from farm to consumer, but the scope of this research is on manufacturing. Within this stage, both product development and the overall system within which it operates are important influences on energy efficiency. These are touched upon here, but require separate attention to cover them properly.

A state-of-the-art review carried out as part of the present research, covering academic, industrial and policy literature and focusing on food manufacturing in the UK, found that long-standing, readily available technologies and measures for improving energy efficiency in the sector are well known and are gradually being implemented according to each manufacturer's investment criteria. Similarly, radically more efficient technologies are also known, and cost and confidence issues associated with their practical implementation on a wide scale are being researched. The many activities and initiatives in the UK are summarised in the most recent measure, a joint government-food and drink industry roadmap and action plan for decarbonisation and energy efficiency (Department for Business Energy \& Industrial Strategy et al. 2017), which draws on evidence from the major government-commissioned research reported by WSP Parsons Brinkerhoff and DNV GL (2015).

The review found a clear lack of data on energy consumption in the sector at process, machine and machine 
component levels (see Online Resource), data which could inform improvement and innovation in machine and process design for both retrofitting and in new equipment. Machine design, and to a lesser extent process design, can be categorised as a space between the well-known measures/ technologies and the radically more efficient. This paper demonstrates the significant potential for energy efficiency improvement available in machine and process design innovation. (Henceforth, 'machine design' includes process design.)

Data acquisition to establish baseline energy use is the first step signalled in the ISO standard 50001:2011—Energy Management Systems (BSI 2012) and in the current draft updated consultation version (International Standards Organization 2017). ISO 50006:2014 (BSI 2015) provides guidance on how to establish, use and maintain energy performance indicators (EnPIs) and energy baselines (EnBs) in measuring energy performance and energy performance changes.

For food products, this data acquisition step can initially often take the form of eliciting and assembling the knowledge of long-standing personnel or experienced consultants in order to identify the processes using the most energy and with the greatest scope for reduction. Reference can also be made to published lists or databases of energy 'hotspots' in manufacturing. Beyond this, appropriate metering of processes and machines, together with data analysis, is needed.

Our review concluded that few food manufacturers in the UK acquire data to process/machine level, and of those which do, there is only partial coverage of their operations. Most companies only have data from their site utility meters, enabling them to produce an overall specific energy consumption (SEC) figure (e.g. $\mathrm{kWh} / \mathrm{kg}$ of output) but nothing at machine level to provide greater intelligence on sub-optimal energy use. The main reasons for the lack of engagement at this level appear to include the costs of hardware, installation and associated software and analysis, whether using internal or external expertise, as well as lack of awareness and priority (see Online Resource).

If machine-level data were to be widely gathered, its value for informing machine design would be limited because it would not enable comparisons between machine designs, for which brand is a proxy. Comparability is also therefore required. If achieved, benchmarks are automatically created and can be used as levers for machine design innovation through a peer benchmarking system.

The remainder of this paper describes a novel system for accelerating and enriching innovation in the design of food manufacturing machines for energy efficiency purposes, utilising aspects of data science and behavioural science to stimulate and inform engineering science. Section 2 describes and exemplifies the potential for machine design innovation to contribute to energy efficiency gains. Section 3 sets out the logic train by which a novel self-sustaining cycle of data acquisition and analysis, peer benchmarking and machine innovation was conceptually built, and the evidence available and needed to prove its validity and robustness. Section 4 states the benefits the system would provide if implemented, bringing in a new level of data transparency, effectiveness and system resilience. Section 5 summarises the journey and the next steps.

\section{Machine and process design: the untapped innovation space for energy efficiency}

This section provides evidence for the effect of machine design on machine and process energy efficiency, from both theory and application.

\section{Theoretical basis}

Various design and quality aspects of machinery and processes convert or use energy, so their design is likely to affect how efficiently that is done. The following are examples (Table 1):

These variables can be significantly different between machine brands designed for the same function(s), leading to energy consumption differences of material importance for food manufacturers' profitability. Examples are oven insulation, material density of moving parts, other materials properties, impeller geometry and pipe layout (see Table 3 ).
Table 1 Examples of variables affecting food machine energy consumption

\begin{tabular}{ll}
\hline $\begin{array}{l}\text { Design aspects } \\
\text { Geometries of machine components }\end{array}$ & Heat losses and recovery \\
$\begin{array}{l}\text { Suitability of machine components related to functions (particularly } \\
\text { type of motors) }\end{array}$ & Process agents \\
$\begin{array}{l}\text { Surface energy and lubrication of machine components } \\
\text { Materials densities of moving machine components }\end{array}$ & $\begin{array}{l}\text { Process sequencing } \\
\text { Throughput }\end{array}$ \\
$\begin{array}{l}\text { Efficiency of machine-embedded power and heat conversions } \\
\text { Quality aspects (definitive reference: IEEE Standard 1159-2009) }\end{array}$ & Ingredient and product properties \\
Power supply (including power factor) & Installation \\
Equipment (particularly motors) & Operation \\
\hline
\end{tabular}


Machines may also differ because machine manufacturers do not adopt the most energy efficient components, simplicity and cost being two reasons (synthetic lubricants and VSDs not tuned for specific tasks are two examples) or because machines are old, although could be upgraded.

We can calculate or model in software the theoretical maximum potential for energy saving for whatever form of energy and energy conversions are involved. However, in practice this potential depends on the means by which energy is delivered to, and interfaces with, machinery and product materials - the system design. Using the lesser known framework of a complete system (Mann 2007a), Fig. 1 illustrates the physics of losses:

Some established innovation tools, based on TRIZ but expanding it using a proprietary approach called Systematic Innovation (Mann 2007b), provide a systematic process for identifying design improvements to reduce or eliminate these system inefficiencies. Often the best tool to start with is the concept of the Ideal Final Result (IFR): what would a perfectly efficient system look like (even though it will not be attainable)? It is then possible to 'backcast' - plot a path towards the IFR using another tool: Evolutionary Technology Trends. These Trends are the result of many years' empirical research and testing in commercial consultancy (Mann 2007b). Figures 2, 3 and 4 show examples applicable to some food machinery functions.

Surface segmentation (Fig. 2), eventually enhanced with active chemistry, provides one means of reducing friction with fluid flows, so could be applied to many food machinery surfaces. This is also an example of the IFR goal of self-action, for example self-cleaning, albeit with the need for an external driving force to take separated particles and molecules away from the surface.

An example of Dynamization (Fig. 3) is supersonic fluid mixing, pumping and cooking - using steam infusion rather than injection (OAL Group). This moves from the use of
Fig. 1 Illustrative points of energy loss in a system (blue boxes)

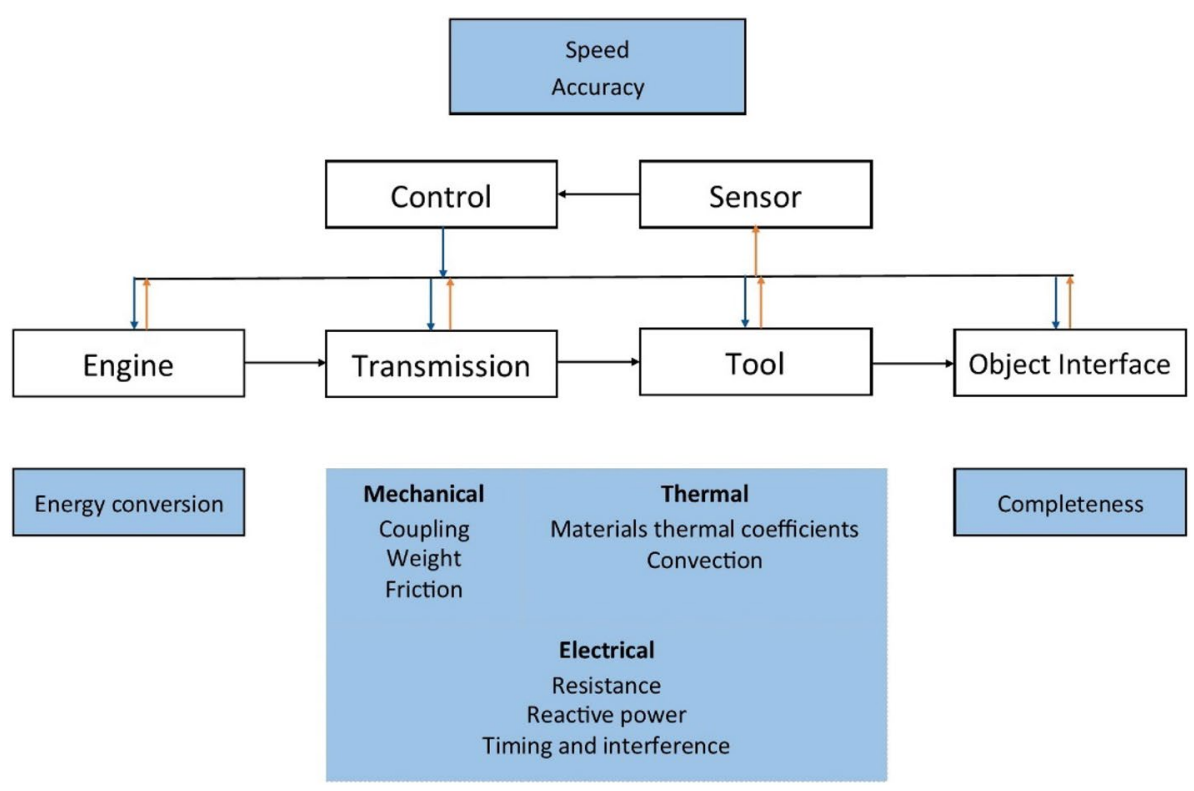

SURFACE SEGMENTATION

Fig. 2 Technology Trend: surface segmentation

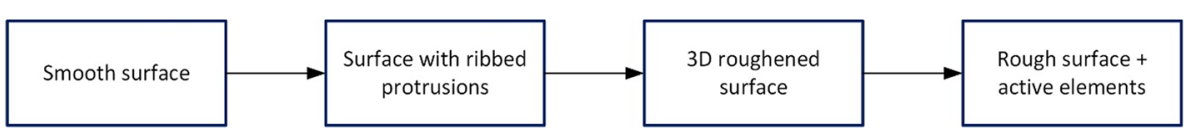

DYNAMIZATION

dynamisation

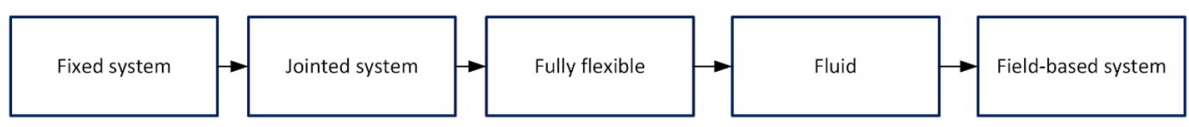


Fig. 4 Technology Trend: object segmentation
OBJECT SEGMENTATION

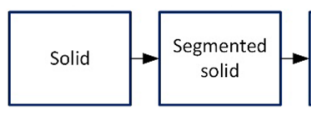

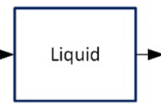

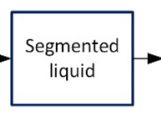

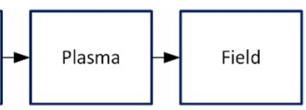

solid materials in impellers to a dynamic working fluid (steam). The interface with the product is completely flexible. No formal energy efficiency comparisons have yet been made-highlighting the need for the system proposed here.

Direct-fired, forced convection ovens use hot air jet impingement through arrays of nozzles to deliver heat to the product such as bread. This design is an example of object segmentation (Fig. 4), in which the object is a gas (air). The same principle can apply to spraying of liquids. Aspects of design such as nozzle-product distance, nozzle diameter and spacing can be optimised for energy minimisation, and recent academic work did this for bread baking, producing a modelled energy saving of up to $10 \%$ compared to the oven type without the modified design (Khatir et al. 2015).

Some overarching trends into which the Trends can be summarised are:

- Increasing precision in time and space

- Increasing flexibility, particularly of the 'Tool' component of the system

- Increasing self-actuation and control

- Decreasing tangibility.

TRIZ and its extension through Systematic Innovation also has a set of 40 'Inventive Principles', abstracted from millions of granted patents and patent applications, which have been used to solve a corresponding set of abstracted technical problems (see Ilevbare et al. (2013) for an overview). These principles can also be used to indicate the potential for energy efficiency gains through improved machine design. A few examples are given in Table 2.

In addition to these, process intensification is a more widely applicable approach which is an instance of Principle 35. It includes '(a) maximising the effectiveness of intra- and intermolecular events; (b) giving each molecule the same processing experience; (c) optimising the driving forces and maximising the specific areas to which these forces apply; (d) maximising synergistic effects from partial processes', all being applicable at different scales (Rivas et al. 2018).

Radically more efficient technologies-at the far end of the Technology Trends-can certainly be included in the datasets to be acquired in the proposed system, but they are relatively few and far between in current food manufacturing. The Trends tool also points us to staging posts in technology development which are more understood and commercially implementable.

\section{Measured effects of design innovations}

Whilst some machine components are subject to Minimum Energy Performance Standards (MEPS) under EU legislation, in addition to the above theory we know empirically that there are differences in energy consumption between machines performing the same function, and Table 3 lists some of these from the database we have compiled. The list includes both commercially available machines which incorporate energy efficiency innovations and experimental results from the academic literature. A useful list of radically more efficient technologies and some machine design innovations, which have been researched in the Carbon Trust's Industrial Energy Efficiency Accelerator programme in the UK, is given in WSP Parsons Brinkerhoff and DNV GL (2015) and in its separate Appendix C.

It is interesting that the information from commercial literature falls short of the quality required for scientific proof of efficiency claims, and in answer to our enquiries, the machinery/component manufacturers were unable to provide such evidence, as several items in Table 3 show. This itself is good evidence for the value of the proposed machine energy database system and its visibility, because such evidence is one benefit the system would provide.

It is instructive to note that Datta and Rakesh (2013) sought to generate a systematic methodology for assessing and selecting microwave combination baking parameters

Table 2 Application of example inventive principles to machine design

\begin{tabular}{lll}
\hline Principle & Technology/product & Originator/owner \\
\hline 2: Taking out & Variable capacity fermentation tank_match tank volume to product & Core Equipment Ltd \\
& volume & Beko plc/U of Cambridge \\
35: Parameter step change & Solid-state caloric materials & Pax Scientific \\
4: Asymmetry & Fibonacci-based impeller design (biomimetic spirals) & OAL Ltd \\
6: Universality & Jet fluid flows for simultaneous mixing, pumping and cooking & \\
\hline
\end{tabular}




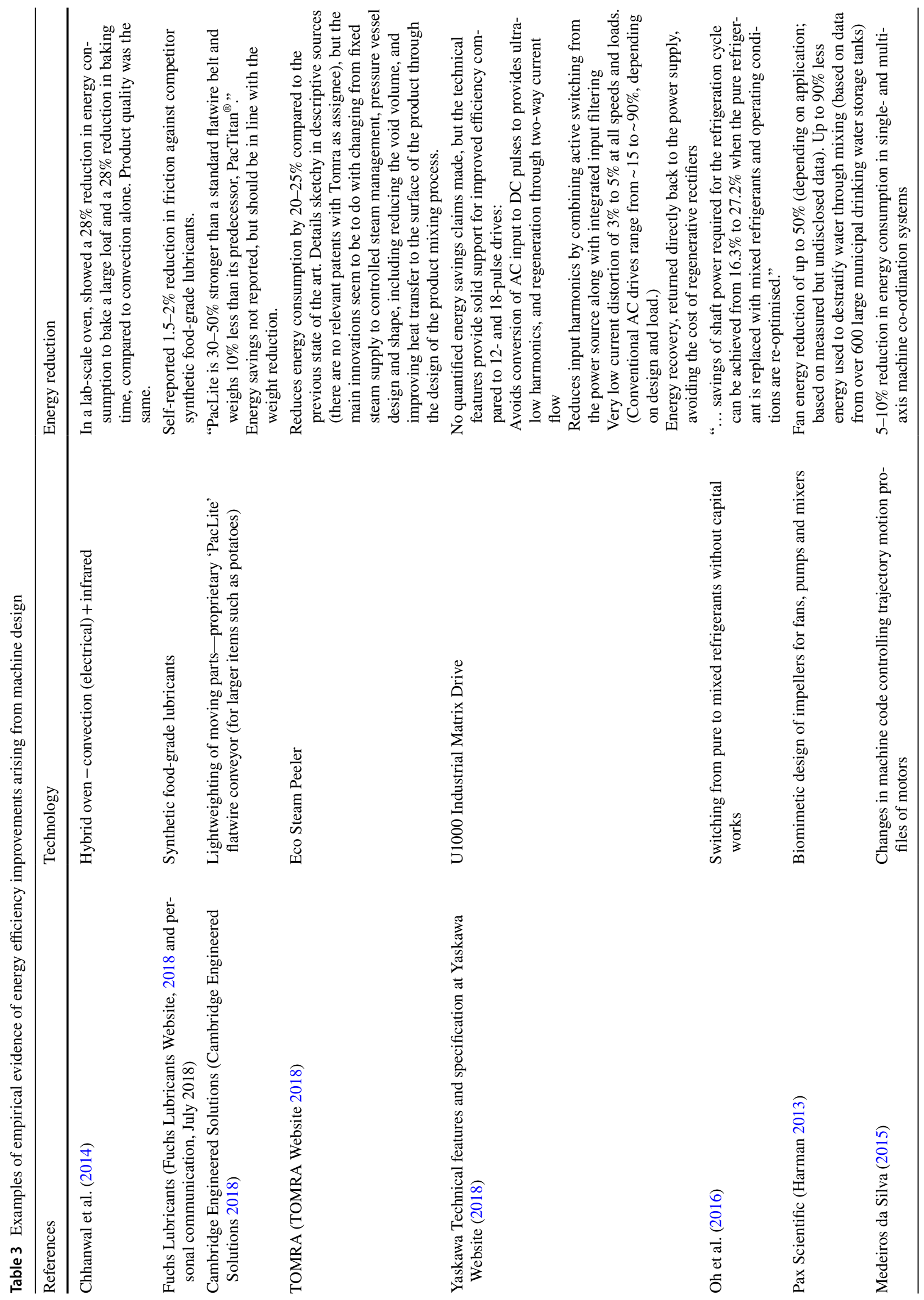


for the many combinations of baking product variables which are possible (ingredients, shape, etc.). Whilst they did not produce any energy comparisons, this indicates that such product-based features may account for some of the energy use differences between machines, which would be a useful finding. Many of these, including shape, are reflected in the most detailed level of the international GS1 classification used for product bar codes.

Lubrication oil is another interesting case. A class of self-lubricating polymers developed by Intech Power Core, a US company, can replace metals for machinery bearings and by definition eliminates oils. The company has not submitted the materials for any formal tests of energy efficiency compared to lubricated metal bearings (personal communication, February 2018). The proposed machine energy database system would provide a low-cost means to do this and accelerate adoption of these materials where appropriate.

At present, the extent and impact of machine design differences in the food industry is unknown. Uncovering these could enable innovation or greater adoption of more energy efficient components or technologies for both retrofitting and in new machine design.

Similar conclusions have been drawn by researchers studying energy signatures of machine tools (Gontarz et al. 2015) and manufacturing in general (Kumaraguru et al. 2014), with respect to life cycle inventory data), which have led to the development of international standards for machine tool design (ISO 14955 series).

As mentioned, data acquisition to detailed level could also include comparisons of incumbent technologies with the radically more efficient technologies, such as the acoustic jet technology mentioned in 'Theoretical basis' section above, and between such technologies for the same functions. Analysis of such detailed data would identify the specific reasons for energy advantages.
Apart from machine and process design, differences in energy consumption could also be due to other factors, which are discussed in 'Other variables' section.

Overall, these findings and analysis lead to a first hypothesis:

Hypothesis 1 - Machine Brand Differences Different brands of food manufacturing machines currently producing the same intermediate or final product consume significantly different amounts of energy.

\section{Testing Hypothesis 1: making machine energy data comparable}

Our first hypothesis uses 'the same intermediate or final product' as the reference point for comparing machine performance. Our review did not identify any previous use of this reference point to enable machine performance to be compared. This section explains how this can be validly and robustly defined, and addresses potential objections to the product as the reference for comparability.

\section{Product definition}

The GS1 classification, defining over 12,600 unique food product barcodes used in over 100 countries (GS1 UK Ltd 2018), can provide tight definitions of intermediate and final products. In a minority of cases, a final level of description may be needed. Examples of GS1 codes for ingredient, intermediate and final products are in the Online Resource.

\section{Function definition}

Whilst the definition of the intermediate or final product is essential, definition of the function being performed by a machine can be helpful. Table 4 gives a taxonomy of food
Table 4 Authors' taxonomy of food manufacturing functions

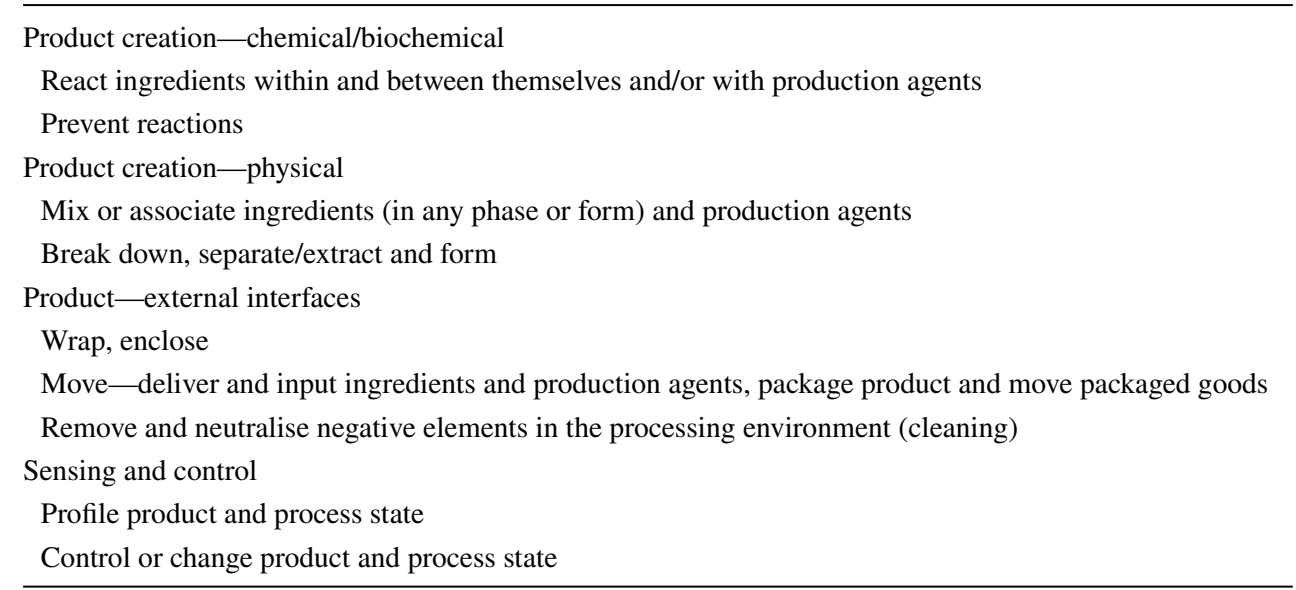


manufacturing functions down to two levels (further levels have been populated to provide a full taxonomy).

One defined product may undergo a series of processes involving some of these functions, whilst another with the same definition may be manufactured in one machine which integrates those functions - an extruder is an example. In the latter case, the comparison may be made by metering energy inputs into each sub-process.

If the sub-processes in a single machine are not separately supplied with energy through the control panel and the fuel/ thermal-equivalent control unit, sub-process metering would not be possible. The comparison then would need to be made by adding the relevant data for all the separate processes used for the comparison product and comparing the total(s) with the total energy consumption of the integrated machine.

\section{Other variables}

It is not necessary to control variations in processes for manufacturing the defined products because such variation is of material importance to the issue of maximising energy efficiency. If a defined product can be produced to the same quality with a different process using less energy, this is a welcome innovation. This is particularly relevant to comparisons of incumbent/traditional processes with radically more efficient but so far lightly deployed technologies (referred to in the 'Theoretical basis' section). ISO 20140-1: 2013 supports the use of the same product as the basis for comparing the 'environmental influence' of manufacturing systems (International Standards Organization 2013).

Some manufacturers may object that qualities of their product, such as taste and texture, are unique and/or superior to other products in the same GS1 classification. A chocolate manufacturer, for example, may claim this due to its unique conching process; another manufacturer may claim uniqueness through secret ingredients. Process and composition seem the main reasons for such claims.

Specific energy consumption (SEC) profiles are informative with respect to these claims. If such unique products have higher SECs per unit mass $(\mathrm{kWh} / \mathrm{kg})$, their SECs per $£$ of revenue are likely to be lower than competing products, because sales will either be large or will attract a high price. This enables an intelligent comparison of products. Claimed high-quality products could be compared amongst themselves, in their own 'league' as it were, stimulating manufacturers to compete on energy efficiency within their peer group. This is akin to vehicles being classified into quality/ functional groups (e.g. city mini, SUV) and their $\mathrm{CO}_{2}$ emissions being compared within those groups. The same applies to other aspects of quality, such as healthiness.

This argument also applies to other production parameters, particularly production rate. Gutowski et al. (2006) showed that production rate for most machined products has the greatest influence on energy consumption, because the overhead of fixed supporting energy-consuming functions (also called indirect energy) is spread over more units of output.

The influence of throughput can be eliminated using regression analysis, showing whether differences in the SEC values obtained are due entirely to throughput differences or whether there are other causes, but only where there are sufficient data points.

The throughput influence is probably less strong in food manufacturing; compared to machine tools, there is less overhead energy in the form of auxiliary processes. Where it exists, it is in the form of pneumatic or hydraulic transmission, and more food processes use electricity. Gutowski et al. (2006) also showed that, for injection moulding, electrically driven components used similar amounts of energy over a range of process rates (Fig. 5).

Heat losses are the other main form of overhead energy in food manufacturing. Product and process materials are also much more heterogeneous than with machine tools.

Nevertheless, where energy economies of scale result in lower SECs for the same food product, this is a material consideration for a manufacturer: what energy and financial benefit could be gained by scaling up production, where possible, or could a higher SEC associated with a lower production rate be mitigated by switching to renewable energy, particularly if it could be on-site? Could efficiency be improved by changing parameters of the product materials, or using a different technology?

This approach of defining only the intermediate or final product by GS1 code to generate energy efficiency comparisons between machine brands avoids the complications

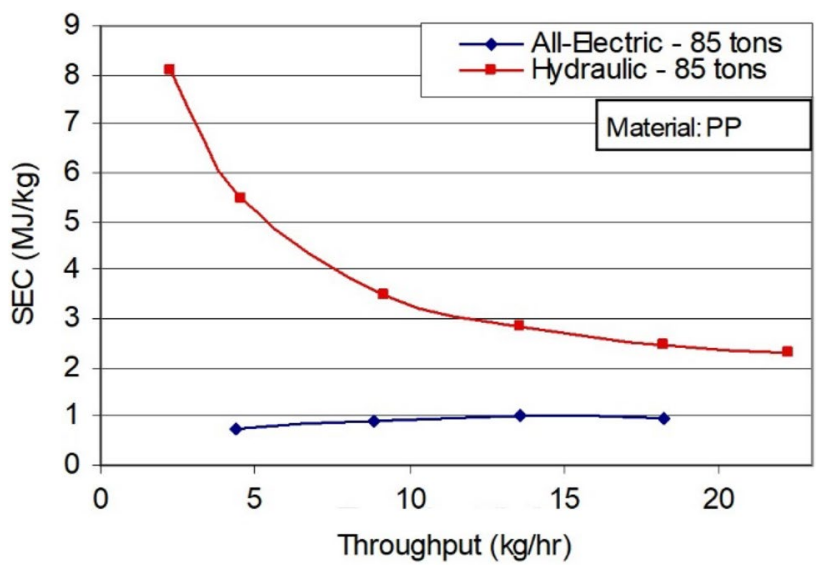

Fig. 5 Virtual elimination of process rate (material throughput) effect for electrically driven injection moulding machines (Gutowski et al. 2006) (reproduced courtesy of CIRP, from 13th CIRP International Conference of Life Cycle Engineering, Leuven, May 31st-June 2nd, 2006) 
of including production parameters, advocated by Cai et al. (2018) with respect to machine tools, in the generation of an energy benchmark, or defining processes (Andersson et al. 2018). Instead, our approach moves production parameters and finely granulated process data to the analysis stage, informing innovation in machine and process design.

Another objection to our comparability metric might be that climate and other factors significantly influence energy efficiency but are outside the manufacturer's control. Again, this is informative with regard to improvement and innovation actions. Such factors should be measured so that analysis of the energy consumption data can be properly informed. Possible conclusions about the influence of a hot or cold climate include:

- Manufacture of the product is best done in the climate requiring the least energy input, so should be relocated.

- The manufacturer should improve insulation of the building and/or machinery, a one-off capital cost which will fall out of operational costs after a period.

- The climate disadvantage could be removed by investment in interseasonal solar heat storage systems (an innovation which might not otherwise have been identified).

- The effect of climate should be removed from the data (by, for example, relating it to degree days) to normalise comparison of the product's manufacture around the world (EN 16231:2012, the European standard on energy efficiency benchmarking, advises that these external factors should be accounted for (British Standards Institution 2012)).

\section{Using comparable machine energy data to stimulate machine and process design innovation}

So far we have assembled evidence of significant potential to improve energy efficiency through machine design innovation, suggested the need for machine comparability in order to identify specific innovation opportunities, and established a robust and valid basis for comparing machines.

On its own, this is not enough to stimulate enhanced innovation activity in machine design. To realise the potential, a system is required to acquire comparable data and use that data to influence machine design activity. This section proposes a structure for such a system and how it would operate.

\section{Possible models}

The traditional method of converting this new opportunity into actual improvements in the field would involve change agents (organisations and consultancies), publicly funded or on a commercial basis:

- Promoting the opportunity to food manufacturers through various channels

- Marketing energy monitoring and improvement services based on the machine energy data, some of which may be subsidised

- Providing those services on a one-to-one basis.

Reliance would be placed on a target proportion of manufacturers responding and engaging in a programme of data acquisition, analysis and improvement actions. They would be expected to pay partly or completely for sub-metering and associated software and services. The benchmark would be the energy-related specifications of the food manufacturers' machines, and the data would show them where a machine was performing below those specifications and how process management could be improved. The lack of external benchmarks would not reveal potential machine design improvements. This is a linear, one-to-one relationship between the supply-side and demand-side, as shown in Fig. 6.

As shown in Fig. 7, the drawbacks of this approach are that it becomes increasingly more costly to sell to each additional food manufacturer, and therefore slower to act and achieve energy efficiency impact, and it is under the control of the supply (knowledge)-side.

An improved approach is to operate at the industry level, pooling food site- and manufacturer-anonymised data to analyse categorised issues and produce machine and process design guides. This is illustrated in Fig. 8.

Such work would probably be publicly funded through one or more projects, as the target industries are unlikely to pay for knowledge which is now efficiently condensed and is less open to being charged for by the hour. An expert supply-side of change agents would be funded for a defined period to promote the opportunity to manufacturers of both food and machinery through various channels, and then

Fig. 6 A one-to-one model of business energy efficiency consulting

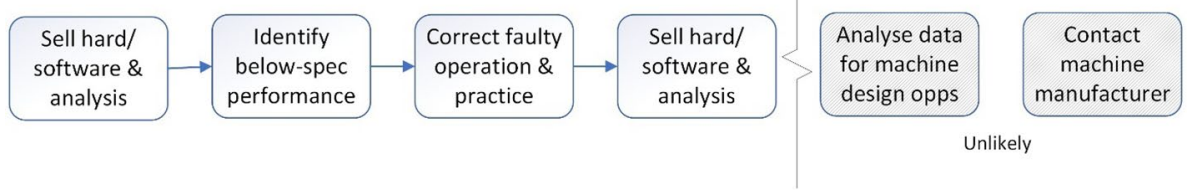


Fig. 7 Drawbacks of the one-toone approach

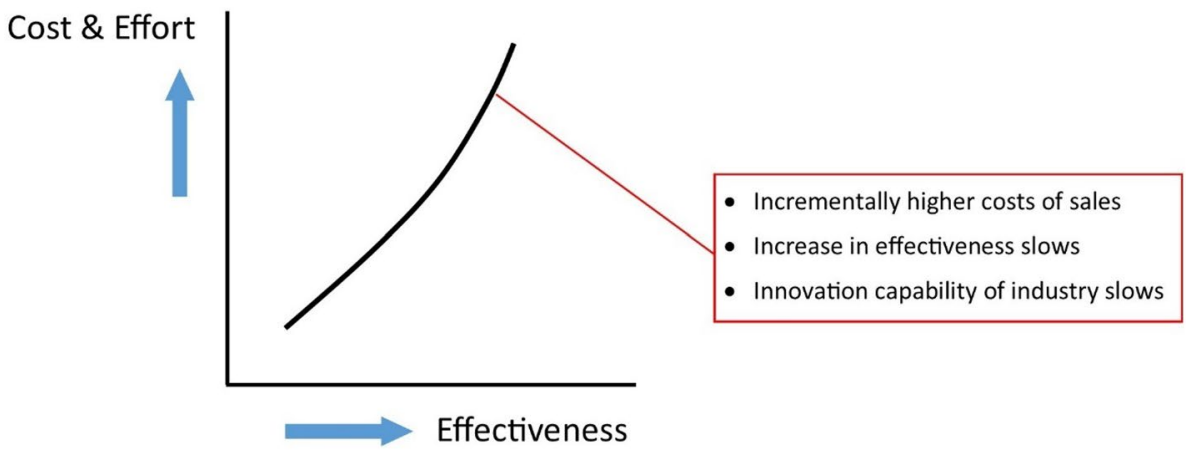

Fig. 8 A one-to-many model of business energy efficiency support

Fig. 9 Drawbacks of the one-tomany approach

Fig. 10 A many-to-many model of business energy efficiency consulting
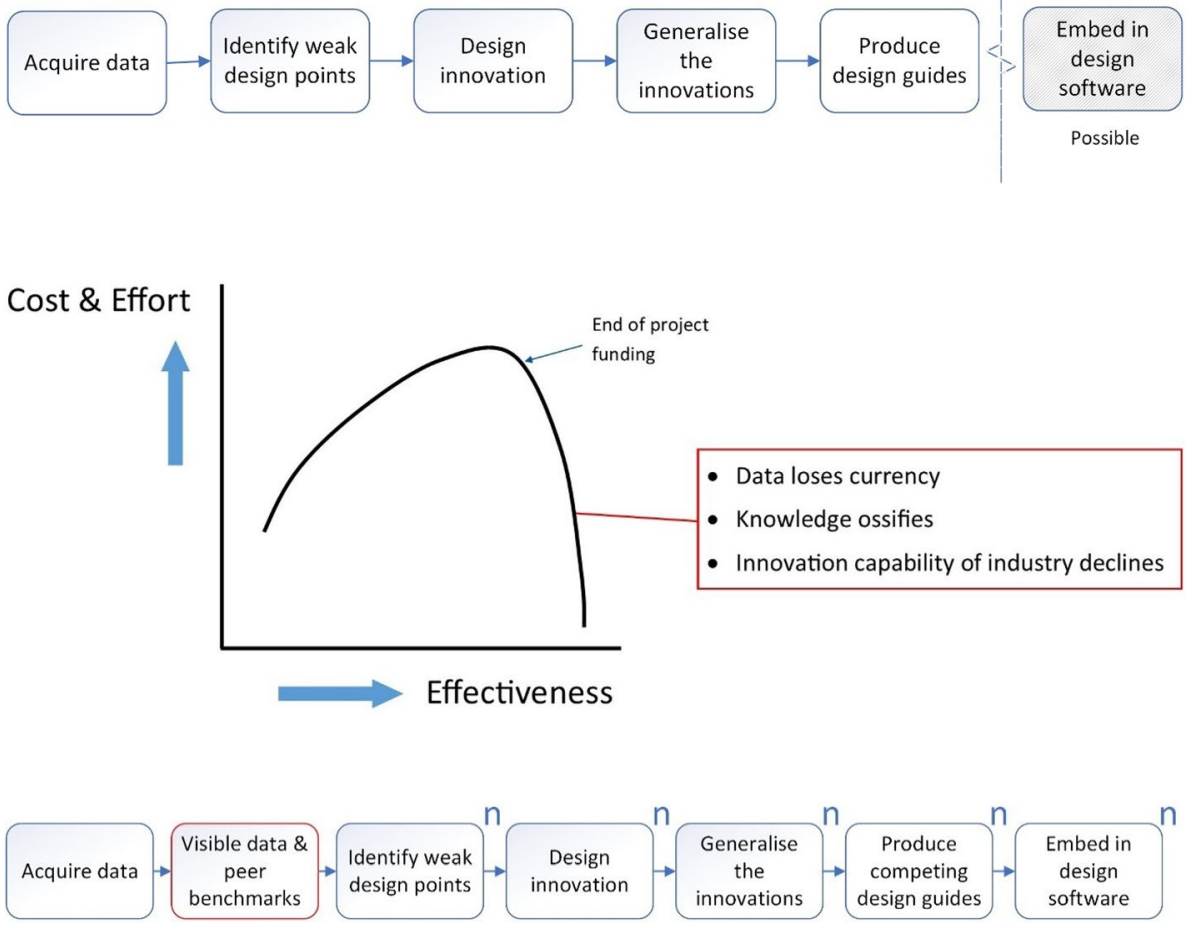

complete the tasks shown in Fig. 8. This is a 'one-to-many' model, with relatively few change agents acting as a unit within controlled boundaries and engaging with the many food manufacturers.

This approach is stronger because it learns bigger lessons from a bigger pool of comparative data, making the insights more powerful, valid and robust, and therefore extending impact further into the future. However, the control of the knowledge and its flow to users is still in the hands of a few, making for slow progress and a limited set of design innovations, and it is reliant on public funding, compromising the release of innovation potential, as shown in Fig. 9:

A more resilient and powerful approach to exploiting this data acquisition opportunity would be not only to operate at the industry level, pooling food site- and manufacturer-anonymised data, but also to make visible to multiple independent value-adding stakeholders the performance of different non-anonymised machines producing the same products. These independent stakeholders, identified in Figs. 11 and 12, function as 'many' change agents. Adding this step to the process has the potential to multiply the impacts on machine design innovation for energy efficiency, as illustrated in Fig. 10:

This 'many-to-many' approach forms the basis of the system proposed here. Our state-of-the-art review did not find any system using any form of 'many-to-many' model. A major reason for this is aversion to data sharing, which is addressed here in 'The challenges of data sharing' section. We also did not find any co-ordinated activity aimed at improving the design of food production machinery for the purposes of improving energy efficiency. 


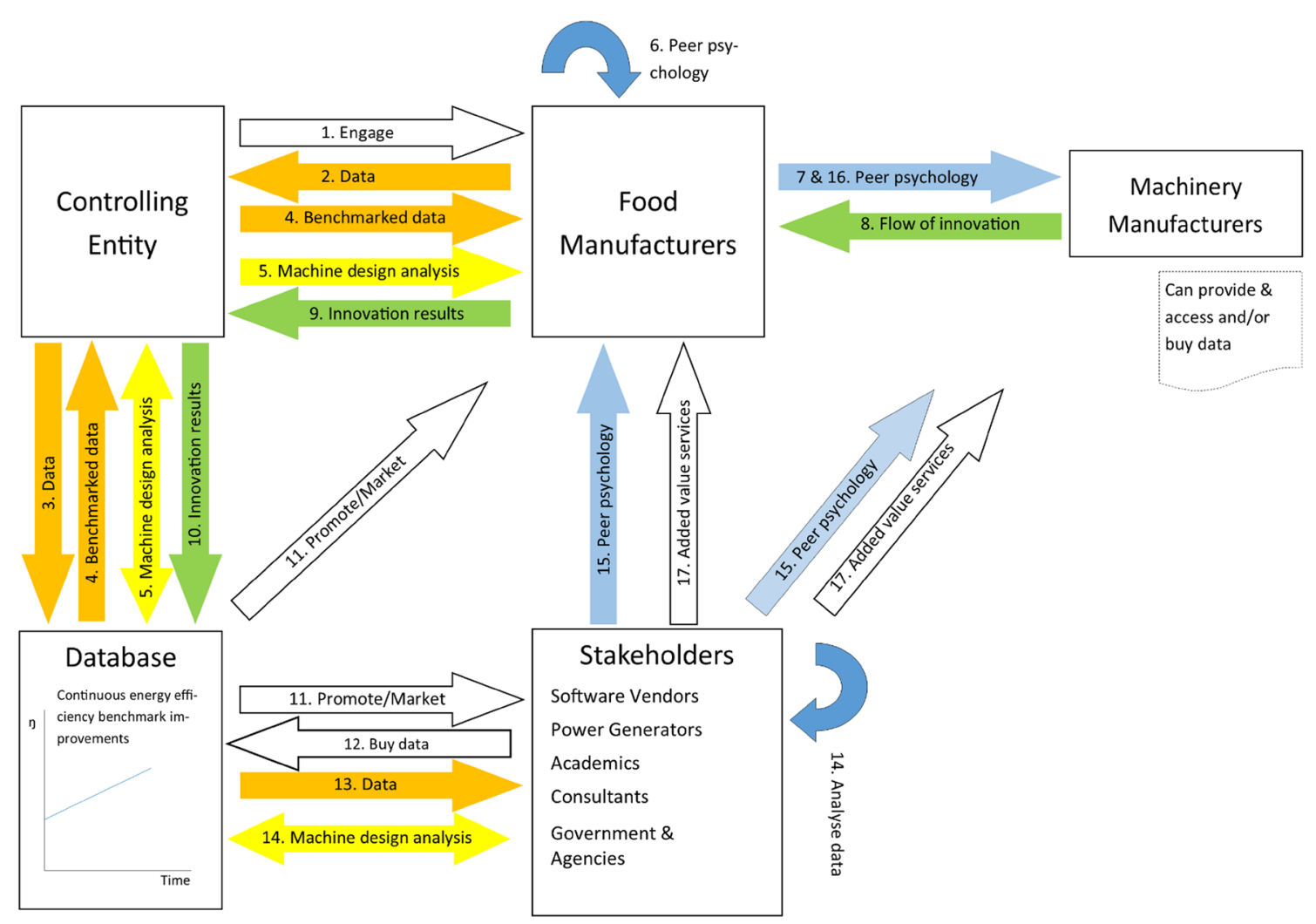

Fig. 11 Proposed Energy Efficiency Peer Benchmarking System

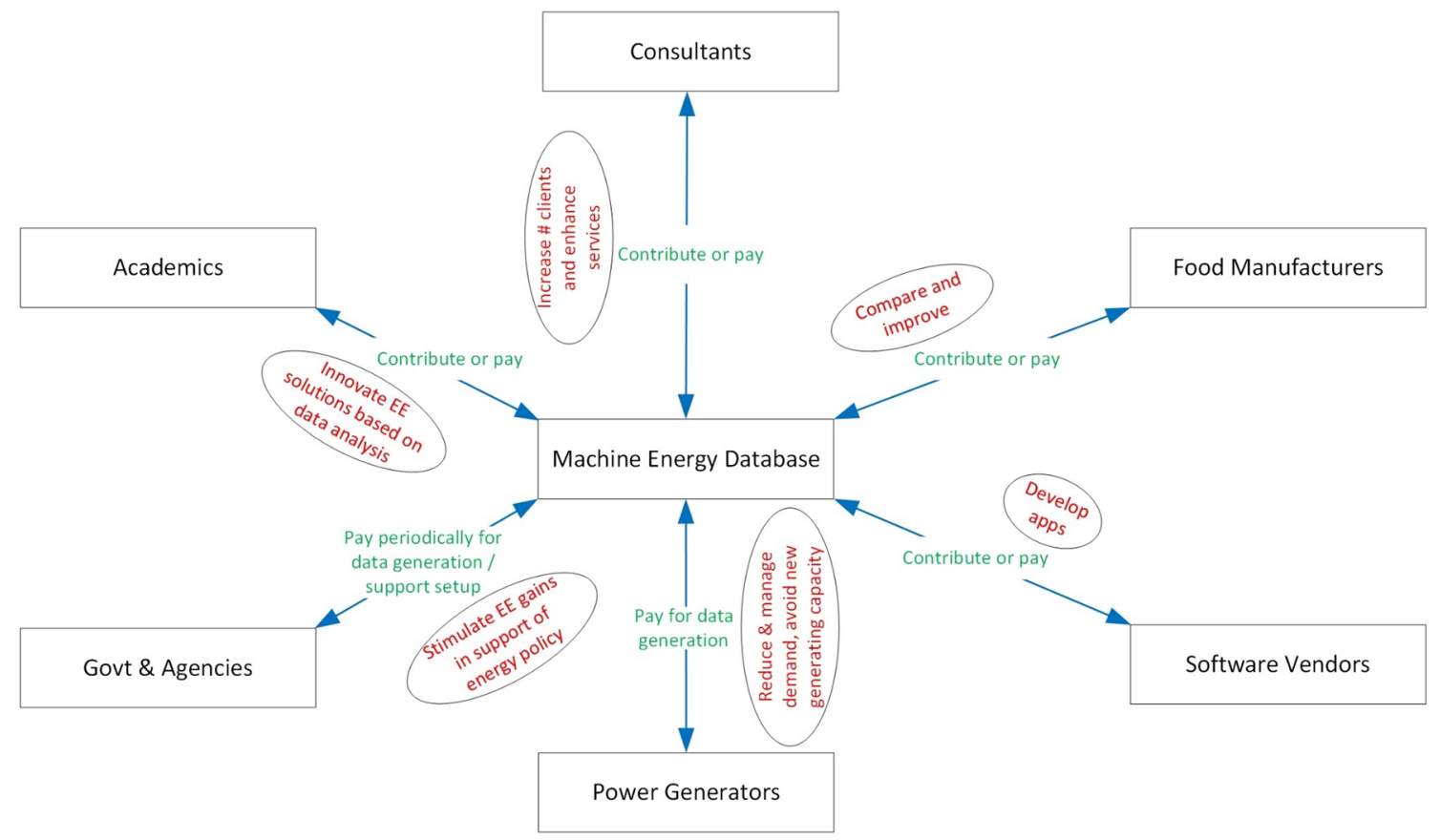

Fig. 12 Value map for a sustainable user-contributory food machine energy database. Red text=stakeholder benefit; Green text=stakeholder contribution; $\mathrm{EE}=$ Energy efficiency 


\section{Proposed system}

Under the proposed system, schematically shown in Fig. 11, data at machine and process levels would be gathered by an entity, which could be a public body, a notfor-profit or a for-profit company. This controlling entity would store the data in a central database, with the manufacturing plant anonymised, but the machine brands stated. The data would be visible in various forms, including as league tables, to manufacturers and supporting stakeholders on terms which would enable the financial sustainability of the system. Analysis of the data, by the controlling entity and other stakeholders, would enable insight into performance and improvement pathways to extend to machine and process design because comparisons would be possible. The system would establish a feedback loop to both the demand-side (food manufacturers) and the supplyside (machine manufacturers, consultants, the R\&D base). The power of peer benchmarking to influence behaviour, proven in other sectors, would be brought into play.

Figure 12 identifies the benefits which would be available to each stakeholder in the system. The stakeholders operate variously within the industry, supporting the industry and at national level.

Data acquisition would be low cost because only a few sets of measurement equipment would be needed; the entity would use the same equipment to acquire data over a number of cycles in each plant and then reuse in the next plant on a continuous basis. The controlling entity would generate income through charges for access to data and for certain analyses. An exception to reuse of measurement equipment would arise where a manufacturer wanted to install permanent monitoring-perhaps for condition or fault monitoring for example-and in this case the manufacturer would own the equipment and allow it to be used for the data acquisition exercise.

The many-to-many approach maximises long-term energy efficiency impact because (a) it creates knowledge

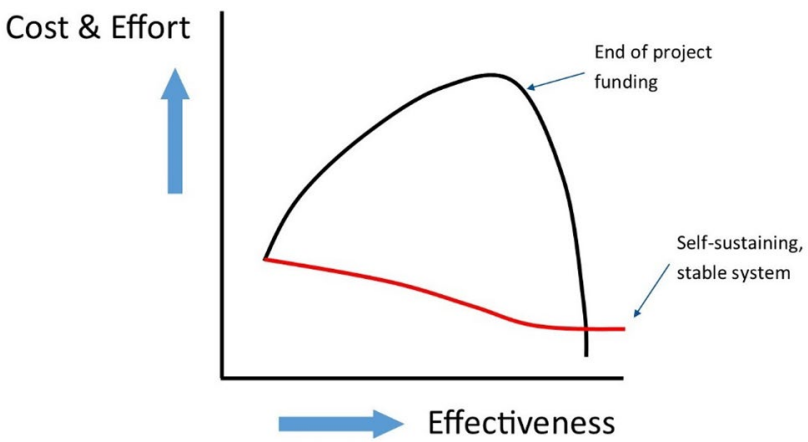

Fig. 13 Benefits of the many-to-many approach (red line), contrasted with the one-to-many approach and insight from a wide foundation of stakeholders, on a many-to-many basis, and (b) it is self-sustaining financially, because many parties have an interest in its availability. It can also easily incorporate the one-to-many approach as one of the flows of value within its many other flows of value. It therefore uses all available senses and knowledge resources, which can be repeated in cycles. This impact is shown in Fig. 13.

Formally expressed, the suggestion is that the system can move from the effectiveness level of the red line in Fig. 14 and Eq. 1 to that of something like the blue line and Eq. 2.

$\mathrm{EE}=\left(\mathrm{iK}^{1.1}+0 x\right) \cdot \mathrm{iQ}$

$\mathrm{EE}=\left(\mathrm{iK}^{1.1}+\mathrm{eK}^{2}+0 x\right) \cdot(\mathrm{iQ}+\mathrm{eQ})$

where $\mathrm{iK}$ is internal knowledge of a manufacturer accruing from private access to its own data, the value of the knowledge depending on the quality of the data; iQ includes internal action-triggering or -inhibiting factors such as motivation, individual and group psychology, and competing priorities; $\mathrm{eK}$ is external knowledge of a manufacturer and other stakeholders in the system, accruing from their access to food manufacturer-anonymous pooled data. This extends visibility. External knowledge is also dependent on quality for its value; eQ is the external counterpart of iQ.

The $10 \%$ and squared effects for $\mathrm{iK}$ and $\mathrm{eK}$ are notional, pending experimental results. They are intended to illustrate the relative power of internal and external data and other knowledge.

This analysis enables second and third hypotheses:

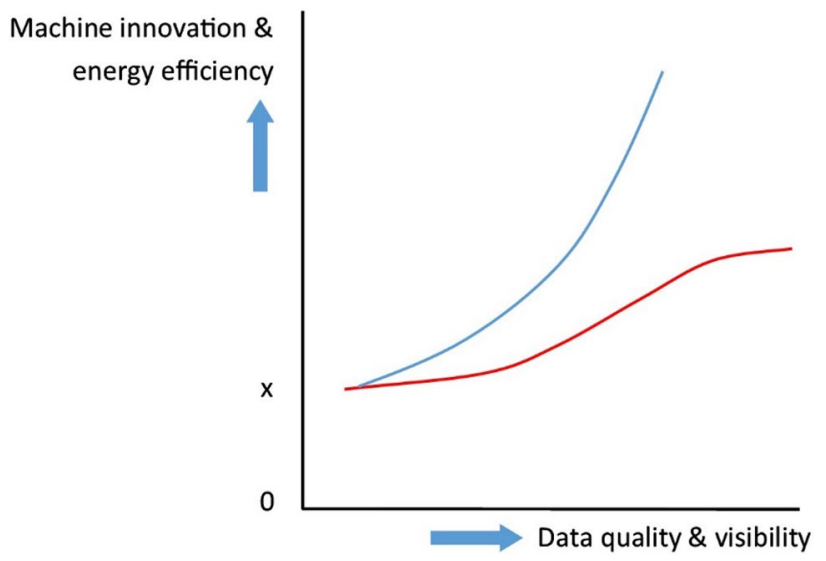

Fig. 14 Effectiveness of internally and externally actuated innovation systems (red and blue lines, respectively) 
Hypothesis 2 - Influencing machine design innovation through visibility of comparative energy data Making comparative machine energy data visible to food manufacturers and other stakeholders stimulates stronger pressure on machine manufacturers than just providing to food manufacturers data for their own machines (i.e. non-comparative data).

\section{Hypothesis 3 - Influencing machine design innovation} through data quality, in the form of machine design and innovation potential analysis Making available to food manufacturers analyses of weak or sub-optimal points in machine and process design with regard to energy efficiency, and of innovations which would improve energy efficiency (which can be generated most effectively and efficiently using comparative machine energy data), has a stimulating effect on innovation greater than making comparative energy data visible.

The system defined here can qualify as 'Big Data' if it involves Volume, Velocity, Variety and Veracity. We will address this below.

Having arrived at a concept which involves mining new seams of information and using it to understand and influence machine design, we now need to complete the arguments supporting the logic train of our hypotheses.

\section{Testing Hypotheses 2 and 3: data visibility and peer benchmarking}

We are positing that visibility of comparative machine energy data to food manufacturers, stakeholders and machine designers should have a significantly greater effect on energy efficiency through machine design innovation than non-comparative data. This is the basis of peer benchmarking. If the comparative data is made visible, comparisons are naturally immediately made.

\section{Peer benchmarking: evidence of effectiveness}

Peer benchmarking adds behavioural science to the data science involved in analytics and the engineering science of machine design. Research has established its effectiveness as a motivator of improvement action (Altham 2007-greener dry cleaning; Oak Ridge National Laboratory 2008 - users of the Motor Master performance database in the US Department of Energy's Industrial Technologies Program; Allcott 2011-Opower Home Energy Reports, enabling domestic energy consumers to see their consumption against peer households; Hahn and Metcalfe 2016-review of the field, highlighting the effectiveness of social norms in changing consumer energy behaviour, as well as another behaviours; Hallsworth et al. 2017-effectiveness of social norms in improving overdue tax payment rates). It has also been applied commercially (e.g. Rappor Metrics Ltd, which gathers views and data from a customer company's suppliers and customers to produce league tables of performance (Rappor Metrics Ltd 2018)) and in government policies, referenced below.

Peer benchmarking involves making visible to an energy user their level and perhaps patterns of consumption ranked among the consumption of their peers. The main psychological factors which underpin improvement (reduced consumption) responses are the desire to be better than peers (competitive instinct) and the desire to fit in with, or not to stand out from, peers (conforming instinct). Peer benchmarking is also called normative feedback where the intention or effect is to establish social norms.

The main contributor to this work in the energy field is the US startup utility Opower (now owned by Oracle). Opower's Home Energy Reports (HERs), sent in the post to domestic energy consumers with their bills, position the consuming household's historical energy use alongside the average energy use of similar anonymous households in the neighbourhood and give quantified suggestions for how energy consumption could be reduced. A comprehensive review of the effect of the HERs on energy use in large populations of 'treatment' and control households in several US states, carried out with Opower's co-operation, found that the average effects of the HERs ranged from $1.4 \%$ to $3.3 \%$ of the baselines' ('pre-treatment' and control) use, with an unweighted mean of $2.0 \%$. This was estimated to be equivalent to the effect of an 11-20\% short run price increase or a $5 \%$ long run price increase (Allcott 2011). The effect increased with higher pre-treatment energy consumption, and there was no rebound effect by which those in the top classes of energy efficient households increased consumption as a result of seeing their comparative performance. The analysis had to assume that all 'treatment' households opened and read the HER documents, but since that is unlikely, the recorded effect was probably greater among an unknown smaller set of households. The effect took several months to reach an approximately steady state, and there was no evidence of any decline in the effect after 2 years of receiving the HERs. This review is supported by other analyses. Working with two sets of households in London, each around 600 in number, whose energy prices were subsidised, UK researchers (Dolan and Metcalfe 2013) separated the two types of information in HERs similar to Opower's (benchmarked consumption information (descriptive social norms) and the advice on how to reduce energy consumption). They found that the benchmarked information:

- alone reduced consumption, by about $6 \%$ compared to consumption before the experiment

- had its largest impact on the day it was received, and then decreased over time 
- did not work when received by email, even with customers experienced in receiving their bills online

- completely eliminated the $8 \%$ gain in efficiency caused by a large financial reward ( $£ 100$ for a $30 \%$ reduction in energy use over 2 months) when the two were presented together. This can be interpreted as a powerful effect of benchmarking information, because it overpowered the influence of a motivator which was stronger when presented alone.

Brandon et al. (2017) confirmed the Opower effect, and their evidence and analysis also suggested a contribution from investment in more energy efficient technologies. Opower (2018), via its Oracle parent, publishes 'Utilities Measurement and Verification Reports of the Opower Behavioral Energy Efficiency and Peak Management Programs', containing over 100 'independent' (third-party) evaluations, which provide consistent supporting evidence of the behavioural effect.

Opower's approach has now been adopted in several countries. The power-related research plus the work from other fields referenced above validates the effectiveness of the relatively low-cost benchmarking intervention for household energy consumption and provides the basis for our optimistic second hypothesis above. However, no field experiment research has been carried out with respect to industrial energy consumers, so the research proposed here would make a start.

There is other non-experimental evidence that industrial peer benchmarking could be a potent means of influencing behaviour:

Regulation (EU) 2017/1369: framework for energy labelling The revised EU energy labelling scheme for energyusing products, which so far has been mainly for domestic appliances. Member States can incorporate any energyusing products within the scope of the labelling legislation.

The energy labelling legislation has resulted in a quick migration of most obligated appliances to the A efficiency category and higher, with only a minority below. Examples are shown in Fig. 15 (von Esebeck and Bush 2018), and Fig. 16 shows that even the worst-performing appliances have reduced energy consumption significantly.

US DoE MotorMaster + 3.0 This 'Best Practices Program' software includes a built-in database of more than 27,000 US motors, enabling comparison of different motors by computing relative costs (including initial, annual energy and life cycle costs) and savings for the motors being considered (ABB 2009). Individuals in a large number of companies in different sectors received the software in a US energy efficiency programme, and some also received training. The evaluation data for the programme are over 10 years old
EU: efficiency classes of refrigerator sales

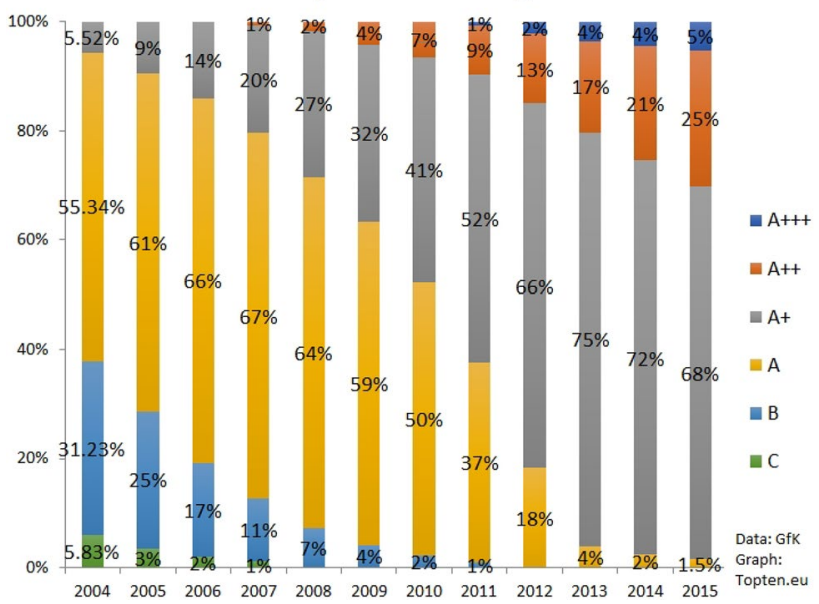

Fig. 15 Sales of refrigerators in the EU by energy efficiency class, 2004-2015 (data source: von Esebeck and Bush, 2018-personal communication, April 2019)

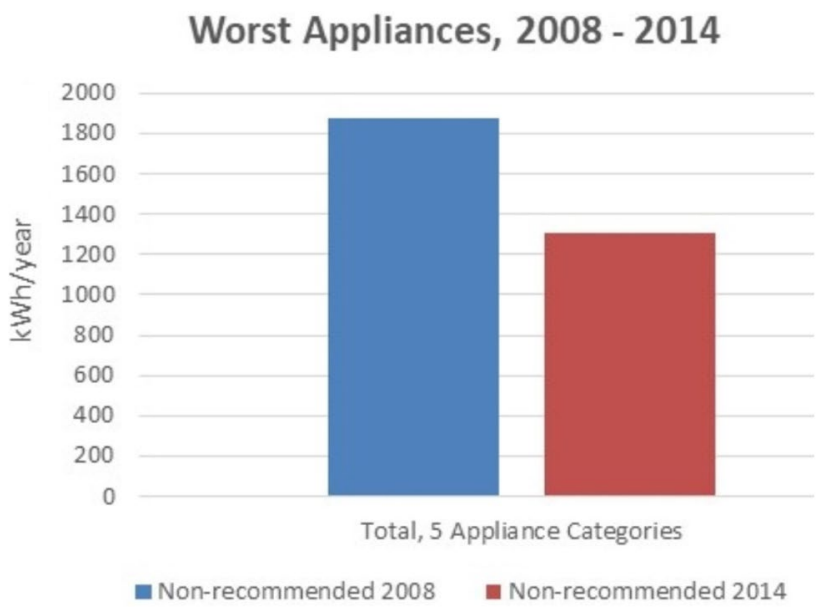

Fig. 16 Average annual energy consumption of the least efficient appliances under the EU Energy Labelling Directive, 2008-2014 comprising TV, dishwasher, washing machine, upright freezer and fridge freezer (data source: Toulouse et al., 2015-personal communication, May 2018)

(Oak Ridge National Laboratory 2008). However, 15\% of respondents (who represented 35\% of those who received the software) reported that the software stimulated them to take implementing actions. Interestingly, the effect for those receiving training instead of the software was over twice as large $(36 \%)$, indicating that the effect of the availability of benchmarking data can be significantly enhanced through personal engagement, as is provided, for example, by consultancy.

At the site level, there are a number of precedents for pooled energy data gathering and assessment against benchmarks. This work began with the Energy Intensity Index 
(EII) for petroleum refineries developed by Solomon Associates from 1980, patented in 2007 (Hileman et al. 2007), and used with modifications principally by Ernst Worrell and colleagues in the Netherlands for iron and steel, chemicals and a range of other industries (e.g. Phylipsen et al. 1998developing energy efficiency indicators for manufacturing; D. Phylipsen et al. 2002-benchmarking Dutch industries against world best and estimating potential savings against the regional best practice).

The Energy Star Energy Performance Index (Boyd 2005—introducing the methodology; Boyd 2017-reviewing the data generated) has taken this further by using plantlevel data to generate benchmark values for the Energy Star for Industry Label. Manufacturing sites can gain certification to the Label if they are within the top $25 \%$ of plants in their sector.

Open Energy Information (OpenEI) (Open Energy Information 2018), a crowd-populated energy data and issues resource hosted by NREL/DOE, is another precedent, but it has no datasets for food, and does not appear to be centrally driven or directed.

In the UK, the government Department for Business, Energy and Industrial Strategy (BEIS) has consolidated several energy/carbon reporting systems into a single streamlined system, but the reporting does not go to process and machine level.

Vigorous research since around 2006 into the energy efficiency of machine tools has not established how reference values or benchmarks can be determined (Cai et al. 2017). The research has led to the new ISO 14955 standard, focused on the environmental evaluation of machine tools and a methodology for designing machine tools with improved energy efficiency, rather than a performance benchmark (British Standards Institution 2014). Wei Cai and colleagues in China have developed a methodology for establishing an energy label for machine tools, using the product as the reference for energy consumption and thereby enabling any combination of machine brands and process designs to be compared (Cai et al. 2017). This is a very recent development so has not (yet) been significantly applied or adopted.

So industrial benchmarking focused on energy use has been seen as important in various countries, but the schemes introduced have all operated at the top level of only the utility or site meter. Apart from the recent developments in machine tools, none have focused on the comparative performance of machine brands.

The closest known system to the one proposed here is in fields related to manufacturing. Veracity.com is a platform, developed by the multinational verification company DNV GL, which has the following features:

- Data can be contributed anonymously and made available to others, with or without charge.
- DNV GL, data owners and third parties can develop apps to analyse, with or without charge, datasets on the platform.

- Peer benchmarking for two energy apps. One of these is 'Eco Insight', in which the use of various resources on ships is continuously monitored. 'Vessel comparisons, fleet benchmarking and market benchmarking are inbuilt' giving sight of 'where you stand and what your improvement potential is.' This is analogous to exposing energy-related differences in machine design.

Veracity differs from the system proposed here in that it does not cover manufacturing machinery and, apart from one-to-one services under contract, Veracity does not involve proactive data acquisition by a controlling entity. This would overcome the problems of data quality which DNV GL has encountered in pilot trials of the system, set out under Barriers 1-4 and 6 at DNV GL (2018).

In the system envisaged here, shown in Fig. 11, food manufacturers would be able to see the brands and models of the machines and components they use ranked in league tables of comparable energy use. In many and perhaps a majority of individuals with executive authority, the evidence suggests that this would stimulate two main behavioural motivators: competitive instinct and conformity or social norming. By activating this psychology, the big dataset could therefore be leveraged to accelerate improvement actions beyond just the greater visibility enabled by its industry scale.

Peer psychology suggests that food manufacturers would begin to exert influence and pressure on machine manufacturers to introduce energy efficiency improvements in machine design, on both a retrofit basis and in new machinery. This would extend to process design because both are linked. Other stakeholders may do the same, particularly government agencies and NGOs with energy efficiency mandates and agendas.

Peer benchmarking has been accepted as a tool by the European Union. Its Energy Efficiency Directive (2012/27) mandates peer benchmarking in industry (Article 25 and Annex VII), but the requirement has not been implemented because a supporting physical, virtual and cultural infrastructure does not yet exist. The European Commission thinks that this will be a slow process (personal communication, January 2018). Italy has conducted limited research to inform construction of this infrastructure (Benedetti et al. 2017), and Germany is developing a peer benchmarking system which places the onus on individual manufacturers to obtain benchmarking data (providing step-by-step guidance), and leaving it open to individual initiative to publish benchmarked data (Ökotec Energiemanagement GmbH 2018a, b). We would suggest that this is not an efficient approach. 
Another possible gateway to benchmark energy data is energy management software. Among the many vendors, only LightApp (2017) showed in our research as offering external comparison of energy consumption, referencing industry best practice. There is no explanation of how such benchmarks are derived. At the machine level, the data are limited by the extent of sub-metering paid for by the food manufacturer.

Data visibility does not have an equivalent Big Data element, but it could be added as a fifth ' $\mathrm{V}$ ' to the definition of a Big Data resource.

\section{The challenges of data sharing}

Participation Sharing data 'horizontally' across an industry carries actual and perceived risks. Lack of participation by food manufacturers due to risk aversion is perhaps the biggest challenge to the successful implementation of the system proposed here. It is the 'threat' element of a SWOT analysis.

The risk associated with a manufacturer's machine energy datasets becoming publicly known (even though the manufacturer's identity is anonymised) is that competitors could match good performance through retrofitting of machines or new purchases, thereby removing competitive advantages in terms of cost and energy security.

The risk calculation is the likelihood of the good performance matching multiplied by the extent and nature of loss of competitive advantage-the severity of the net negative impact.

It can be assumed that the likelihood of matching is high, since that is the effect of peer benchmarking. The rational calculation of a food manufacturer as to whether to participate should then be governed by (a) their knowledge or belief about the extent to which they would, respectively, be a 'matcher' and be matched-in other words, where they are in the league tables of energy performance for their products - and (b) if they are matched, how much of a competitive gain that would be for their competitors.

For (b), this depends on the characteristics and circumstances of each food manufacturer, and there are several considerations they each need to weigh. These are listed under different circumstances in the Online Resource for this paper. As a multivariate problem it is not therefore possible to produce a definitive answer to the question for all food manufacturers. A formal method of decision-making could involve assigning positive or negative values to each of the relevant considerations in the Online Resource and then multiplying them together to produce a positive or negative score-akin to a TOPSIS evaluation (Hwang and Yoon 1981).

Factor (a) above involves uncertainty. Figure 17 shows the five possible sections along a scale of uncertainty within which a food manufacturer could find themselves.

Each section of the scale or category of manufacturer is briefly described below. Typically, the thoughts will be those of the Energy Manager:

(1) Pre-participation-The dominant force is uncertainty about what competitors might do as a result of seeing the ranked anonymous data. The Energy Manager cannot be sure about this, so can only focus on what the company will get out of participation. The eight factors listed in the Online Resource (OR) to this paper under this circumstance strongly support participation.

(2) Worse - "From the data received, or what I know or suspect already, I'm worse than others." The peer benchmarking evidence supports a participation reaction incorporating some or all of seven factors listed in the OR under this circumstance.

(3) Better- "From the data received, or what I know or suspect already, I'm better than others." The eight factors listed under Circumstance 3 in the OR, supporting participation, would need to be considered.
Fig. 17 Distribution of food manufacturers by energy efficiency for a defined food product

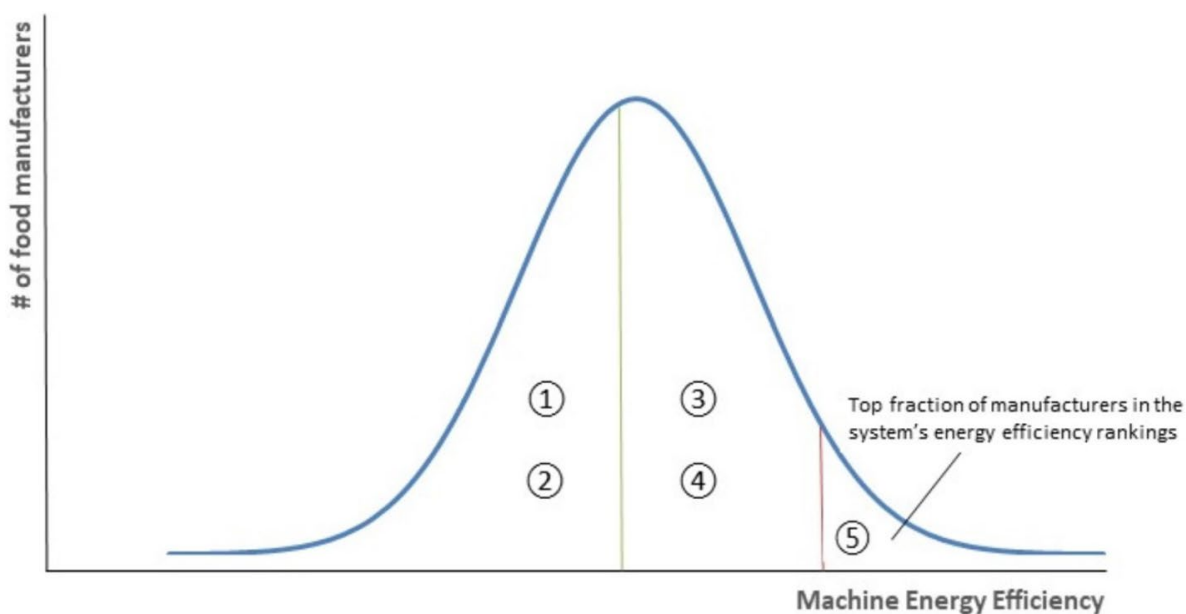

Machine Energy Efficiency 
(4) Improved- "As a result of seeing my comparative data, I've just invested in retrofitted machine component improvements."

There is less evidence about behaviour in this transitional state. An intuitive analysis would say that the manufacturer could afford to disengage from the benchmarking system for a period, but that this position would not persist. The Circumstance 3 factors would also apply to this category.

(5) Leading-“'I know I'm the best because I have the most advanced technology which has been shown to have the lowest energy consumption."

Figure 17 indicates that Group 5 is likely to form only a top minority fraction of the food manufacturing population.

Some of this top fraction of manufacturers in the system's energy efficiency rankings may perceive significant risk in sharing their anonymous data, where they are sure they have invested in the highest efficiency machines. The remainder of the top group may not be so sure, and/or may take into account the three factors under Circumstance 4 in the OR.

Uncertainty for the whole population could drive participation. The decision about participation rests on either maintaining the status quo or opening up the advantages. The advantages could equally be seen as avoiding the opportunity costs of non-participation, listed in the form of the factors in the OR. It is suggested that, for the majority of manufacturers, uncertainty and these alternative considerations are candidate drivers of participation in the system.

The issue can be formally characterised using the classic game theory scenario of The Prisoners' Dilemma, in which various degrees of penalty or freedom for two prisoners are possible outcomes, but they depend on the combination of independent confessions and non-confessions they make. Substituting sharing and not sharing data for confession/ non-confession, Fig. 18 shows the choices and the outcomes for the two broad categories of food manufacturer we have discussed above.

For the advanced group, their interest is generally in keeping their data to themselves, because they will retain and not jeopardise their assumed advantage on energy consumption. For the non-advanced group, there is no benefit

\begin{tabular}{|l|l|l|l|}
\cline { 3 - 4 } \multicolumn{2}{c|}{} & \multicolumn{2}{c|}{ Non-Advanced } \\
\cline { 3 - 4 } \multicolumn{2}{c|}{} & Share data & Keep data \\
\hline Advanced & Share data & Lose/Gain & Lose/Not gain \\
\hline
\end{tabular}

Fig. 18 Prisoners' Dilemma outcomes of data sharing. Advanced (first of each pair): manufacturers confident they are at or near the top of the EE league. Non-advanced (second of each pair): Manufacturers without such confidence from keeping their data, but a likelihood they will gain by sharing or pooling it in the machine energy database.

As we have suggested, the non-advanced group is likely to be far larger than the advanced group in numbers of companies and by other measures such as aggregate turnover, making it likely that the database would have sufficient data to be useful.

The advanced group's guarding of their data may also be undermined by manufacturers of the advanced machines they have invested in. The interest of these machine manufacturers is the direct opposite of their food manufacturer customers-they want to maximise sales and thereby spread the energy efficiency gains to others. The machine manufacturers would therefore be motivated to submit qualifying data to the database from their own reference production runs.

Validation of the power of these participatory drivers could easily be made by consulting a representative sample of food manufacturers. However, there is a risk of a false negative response, leading to inaccurate conclusions about the viability of the system proposed here. If presented to them only verbally and/or on paper, manufacturers may take a risk-averse view, not having seen any actual data to compel their attraction. If actual data were collected and presented in a ranked form as described in 'Peer benchmarking: evidence of effectiveness' section, this would be more compelling and would be a full presentation of the system. We are now moving from system design to the psychology of system adoption, which is the limit of the current paper.

Data security In addition to the fear of a reduced energy cost advantage from anonymous disclosure of comparative machine energy data, some food manufacturers may be concerned that disclosure would affect their reputation and perhaps their rating in their customers' procurement scoring systems if the security of the data was compromised. The issue of trust has featured in two recent UK reports (Hall and Pesenti 2017; Maier 2017) and led to the recommendation that a 'Data Trust Support Organisation' (DTSO) be established to support the expansion of digital technologies in manufacturing, particularly through the development of 'data trust' standards for data sharing.

The controlling entity for the system proposed here would need to know the source of each dataset in order (a) to verify it as genuine and (b) to interrogate it should any questions or problems arise. The necessary knowledge base is data science and cryptology, again at the limits of this paper's scope. Among the range of solutions, the data source would be encrypted and could be held by a third party providing escrow-type services (such as the proposed DTSO), and/ or some form of distributed storage using blockchain could be used. The latter could involve protocolled data storage on a dedicated server controlled by each contributing food 
manufacturer, with access only to database subscribers. This would allow the database controlling entity to access the source information with permission from the data source when necessary.

Identity Beyond security considerations, the proposed system would not disclose the identity of food manufacturers, but the risk could persist if the identity of a manufacturer could be deduced from the product forming the reference point for a dataset and/or from the brand and model of machine used.

The brand/model clue could be removed by also anonymising the machine brands, just denoting them by a reference code instead. Each food manufacturer would receive their data records, and they would of course know their machine brand(s) so would be able to exert pressure or influence on their suppliers. Other stakeholders would be able to analyse the data for each anonymous machine and, with limitations, associate aspects of the data with machine components and processes. Machinery manufacturers or their food manufacturer customers could choose to disclose to the analysing community their specification sheets to assist with design innovation.

The product clue to a food manufacturer's identity would be present if there were only one manufacturer of that product in the territories covered by the database, but this is unlikely, and data could be set only to be available to database subscribers if there were datasets from at least two manufacturers. It would then be difficult to deduce identity based on machine performance.

\section{Experimental variables}

Since peer benchmarking of machine energy efficiency has not yet been reported, the Proof of Concept of the proposed system and in particular Hypotheses 2 and 3 would constitute an experiment. This paper describes a proposal at this stage, so details of the experimental setup will be left for the report on the experiment, but the main variables on peer benchmarking will be as follows:

Dependent variable:

Independent variables:
Energy consumption differences (league tables) by machine brand for a defined intermediate or final food product.

Food manufacturer behaviour following sight of comparative data (Hypothesis 2)

Food manufacturer behaviour following sight of analysis of the data and the potential for machine and process innovation (Hypothesis 3).
Control variable:

Baseline variable:

Food manufacturer behaviour following sight of their own data.

Food manufacturer behaviour prior to sight of any data from this experiment ('pre-treatment').

The variables for Hypothesis 1 are different

\section{Testing Hypothesis 3: data quality requirements}

Hypothesis 3 posits that major aspects of data quality are diagnostic analysis of the reasons for the poorer performance of machines compared to others and then design innovations, specified to varying degrees and in various forms, including patents (which would clearly need appropriate allocation of rights, preferably to incentivise all relevant stakeholders). This section sets out important requirements for these outputs.

\section{Diagnostic and innovation analysis}

As we saw in the 'Machine and process design: the untapped innovation space for energy efficiency' section, the canvas for design innovation is very large and the improvement potential is also significant. The analyses and innovations made possible by sight of the data would come from the controlling entity and some of the stakeholders accessing the data. Machine manufacturers would also produce such outputs, but it is the influencing effect on them with which Hypothesis 3 is concerned.

These outputs can be enhanced by granularity. The energy efficiency effects of machine design can be seen in even the finest details of machine performance, whether segmented by time or space. In electrical systems, voltage and current can vary by phase and improvements can be designed by phase. In thermal systems, fluxes can vary with differences across material areas and volumes as well as over small time periods. Small inefficiencies can accumulate rapidly. The more precise the data and the causal analysis, the more credible the conclusion will be and hence the strength of influence.

The analyses which could be carried out on the data would produce values for the following key electrical and thermal performance parameters:

\section{Electrical}

- Current and voltage separately over time

- Power over time, which can be useful separately to energy consumption values

- Specific energy consumption (SEC, see 'Other variables' above) 
- Power factor

- Harmonic distortion

(As discussed in the 'Other variables' section, the indicator of use to the food manufacturer is SEC.)

\section{Thermal}

- Thermal flux in relation to product and equipment materials and process fluids

- Specific enthalpy, entropy, Gibbs Energy, Helmholtz Energy and exergy.

Figure 19 shows these values in one possible commercially available program associated with leading edge terminal sensors:

A particularly useful output would be signatures expressed using an appropriate selection of these values for specific types of machine or machine components performing specific functions. This would be possible due to the collection of many samples, enabling an increasingly valid mean for a normal distribution of values to be established. As well as being useful inputs to modelling innovations in machine design, such signatures would also be useful in the fields of process automation, machine learning and nonintrusive load monitoring (NILM).

\section{Data acquisition protocols}

One advantage of pooling anonymised data across an industry is that the comparability of the data can be assured. In the present case, we have established that the GS1 definitions ensure that the same reference output is being used to compare machines.

In addition, a consistent valid and robust protocol can be used to collect the data, eliminating any false conclusions due to the use of different types of monitoring equipment or installation details. This contrasts with the heterogeneous nature of the current system for industrial data acquisition using sub-metering, which does not permit formal comparability.

Use of a common protocol supports an independent controlling entity collecting the data rather than manufacturers. Whilst third-party assurance companies could be accredited to use agreed protocols, the disadvantage is that they would

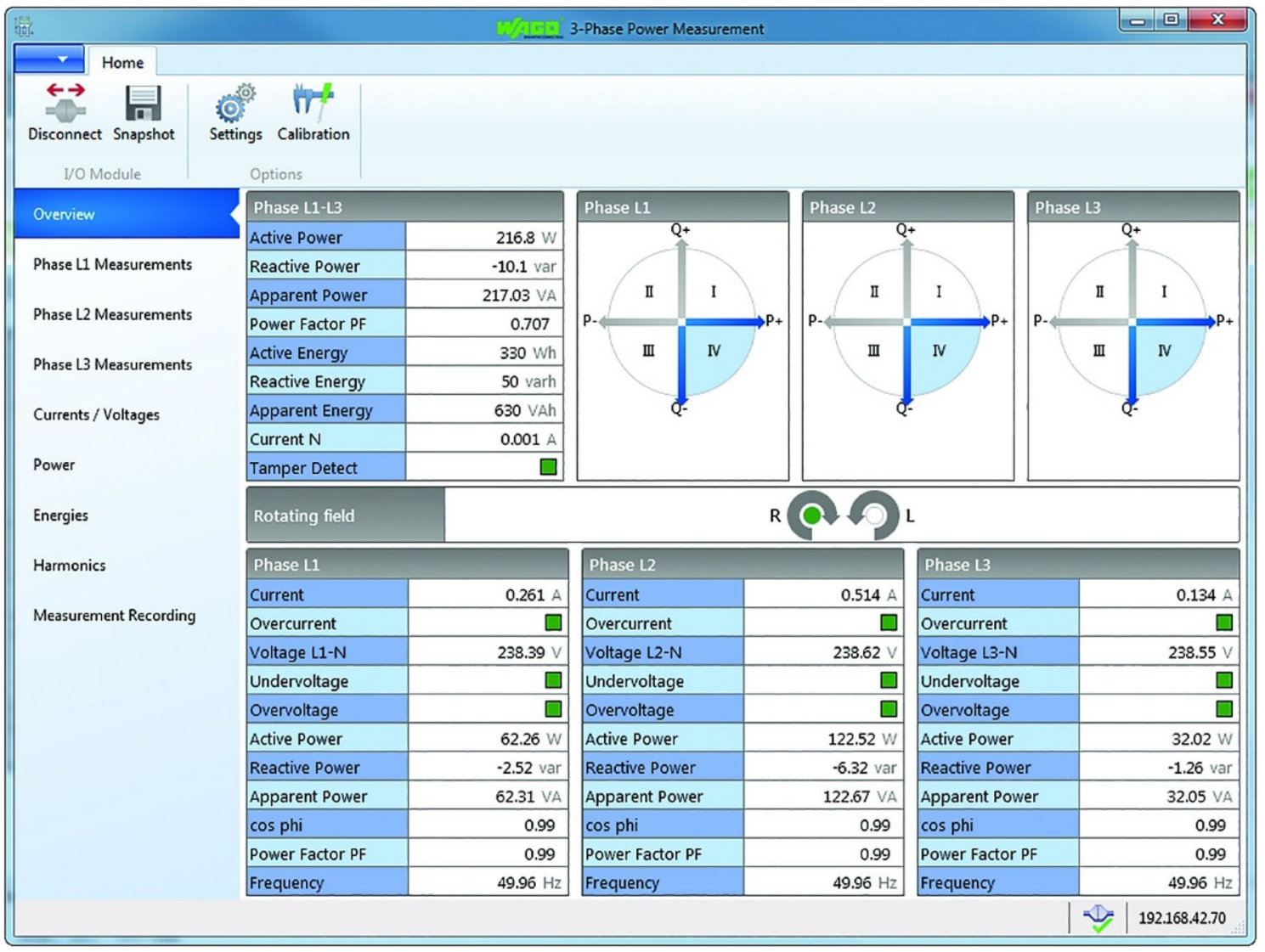

Fig. 19 User interface and electrical parameters available in one possible package using control panel terminals (Image (C) and courtesy of WAGO Ltd) 
charge the controlling entity, which would antagonise the financial sustainability of the model.

There are several protocols for data acquisition, format, storage, analysis, etc., which could be used or adapted. These include:

- Environmental Technologies Verification (ETV) scheme (Europe)

- International Performance Measurement and Verification Protocol (IPMVP) (USA)

- EN 16231:2012

Energy efficiency benchmarking methodology

- BS ISO 20140 series

Automation systems and integration-evaluating energy efficiency and other factors of manufacturing systems that influence the environment

\section{- ISO 50006}

Environmental Management Systems: measuring energy performance

Data quality is the 'Veracity' and 'Variety' elements of a Big Data resource. Variety is provided by the large number of intermediate and final product definitions in GS1 and the potential for a large number of competing machine designs for manufacturing them.

\section{Data quantity}

The quantity of data in the system has two functions-scientific and practical. The scientific function is proving the power of peer benchmarking, and this has been discussed in the 'Testing Hypotheses 2 and 3: data visibility and peer benchmarking' section. The practical function is the influence it can exert on those who can effect change towards greater energy efficiency.

The strength of influence of comparative machine energy data on design innovation seems likely to be proportionate to the number of datasets, where a dataset comprises data for one machine brand manufacturing a GS1-defined food product.

The intended use of the dataset is to identify reasons for differences in energy consumption, principally concerning machine and process design, but also environmental and operational management. Under the envisaged system, the reasons will be identified by both the system operating entity and other stakeholders in fluid interaction with the data and perhaps each other. Food manufacturers are likely to be the most common influencers on machinery manufacturers, though some of the latter will be self-motivated and some will be influenced by other stakeholders. The influencing parties will probably not require a statistically representative sample of datasets in order to begin exercising their influence-even one dataset plus a causal analysis may stimulate them-but more datasets will provide an increasingly normal distribution of machine consumption for each defined product. This will provide increasingly higher confidence that underlying causes exist for energy consumption differences, and will enable more powerful conclusions about the causes to be drawn.

The proposed system would increase the quantity of data far above that currently achievable by individual software vendors or consultants using just their client data.

This aspect is the 'Volume' element of a Big Data resource. (The other Big Data ' $V$ ' is Velocity, which refers to the rate of data acquisition as well as its analysis. For the purpose of influencing machine design for energy efficiency innovation, this is in general not of practical value. Exceptions would be where machine design allows near-real time responses to data from other machines elsewhere which are manufacturing the same defined product, but this would be hard to achieve and the benefits uncertain.)

\section{System impacts}

The main intention of the proposed system is to leverage active and latent capabilities within and between stakeholders in the food and drink manufacturing value chain for energy efficiency gains. The design of the system can achieve this by collecting, assembling, analysing and exposing data which is currently not visible. Peer benchmarking is the main mechanism identified for achieving this effect, and a low-cost arrangement has been described. A more conventional, more expensive but complementary method is teaching or mentoring using design lessons unearthed from analysis of the data. The biggest effect may be achieved by using both within the same package.

Once the relevant executive or team has absorbed the meaning of the data and system outputs such that their thinking moves towards action on energy efficiency, the machine manufacturer is the focus of attention. Most of the resulting innovations are likely to be realised through retrofitting of existing machines, otherwise in new machine designs. Some comparisons involving radically more efficient technologies may involve the food manufacturer planning a future stepchange technology investment.

Finally, to complete the view of the whole system envisaged, paying for energy efficiency innovation in machine design will be, as for well-known technologies now, a big barrier for many companies, including larger businesses. Innovation in the finance field is derisking energy efficiency for investors by bundling energy efficiency schemes and providing third-party assurance with respect to achievement of projected savings, and therefore the cash flow to provide a 


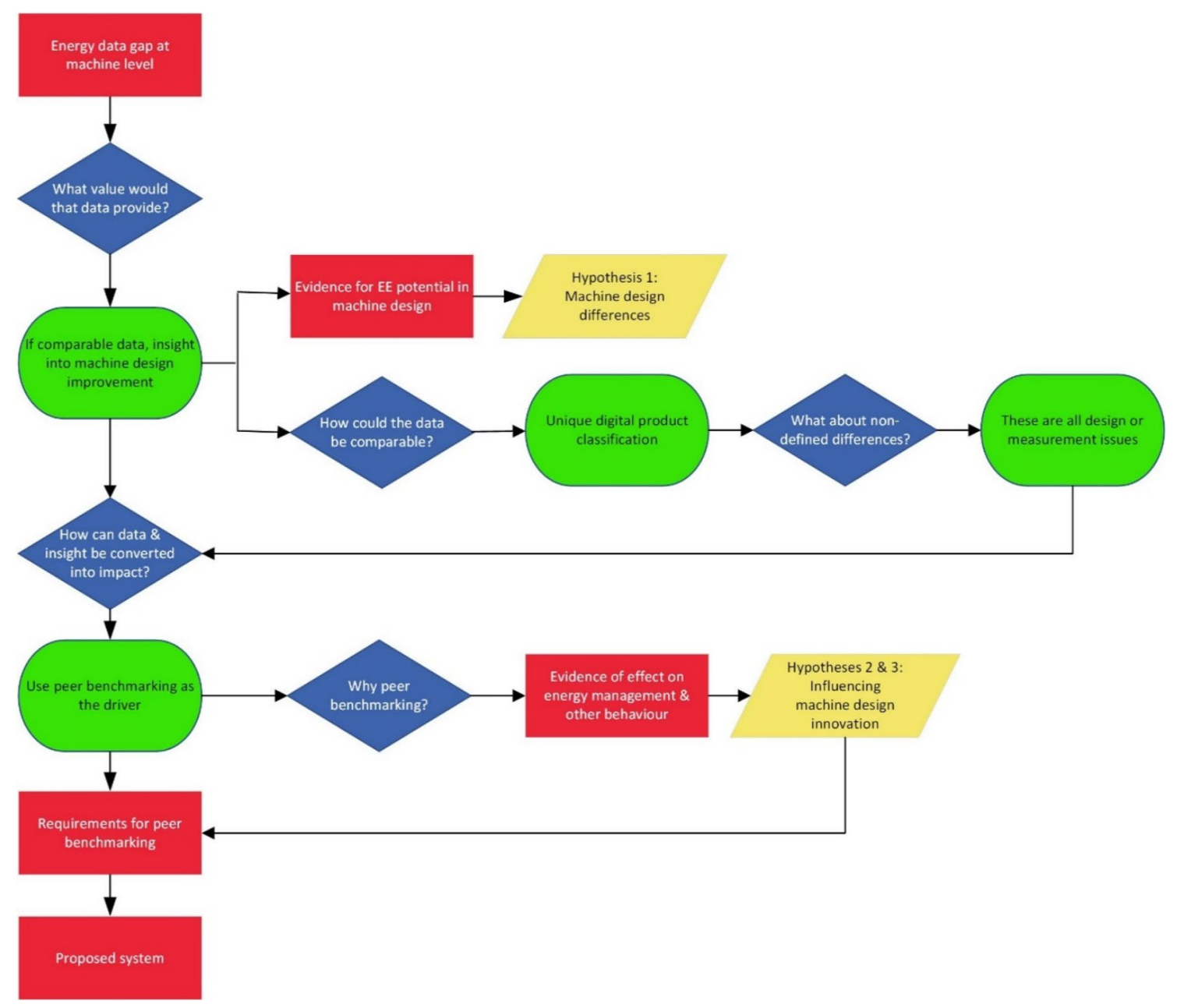

Fig. 20 Key stages in construction of the proposed energy efficiency innovation system

return. A leading example is the Investor Confidence Project (ICP) and its Investor Ready Energy Efficiency (IREE ${ }^{\mathrm{TM}}$ ) scheme (ICP 2018). To date, this has been applied to buildings, so the next opportunity which the proposed system could enable is for production machinery. Under IREE, the finance is secured on the savings, not physical assets as in loan schemes such as that run in the UK by the Carbon Trust and Siemens. The advantage of this is that, under imminent new accounting rules in the UK, physical assets will have to go on the balance sheet, whereas intangible assets will not.

The proposed system has the potential to strengthen energy efficiency innovation capability principally within food and machinery manufacturers, but also within other stakeholders in the system. The increased attention to continual improvement in a learning community should support an enhancement of knowledge, which is demanded by policymakers in the UK (Department for Business, Energy $\&$ Industrial Strategy et al. 2017).

\section{Conclusion and next steps}

This paper has described the emergence of a system of influence and leverage for energy efficiency in food manufacturing from a train of logic which began with the observation that little was known about energy consumption at the machine level. The simple idea of acquiring such data required that this be done at low cost and that the data be used productively. Machine energy data would be useful for identifying machine running problems, but its analysis, down to a fine resolution where necessary, could also inform machine design innovation for energy efficiency gains. The potential gains from such innovation as well as evidence of actual significant implementations were elucidated. Data science—diagnostic and prescriptive-informs engineering science.

However, it is difficult to convert analysis of individual machines on a single site into insights for design innovation to deliver energy efficiency gains if there is no benchmark performance and design to compare against. A major brake 
on the value of machine design innovation is that it can exist in its own bubble, capable of comparison with previous versions of a design but not easily benchmarked. Comparative data were therefore needed.

This brought into play the use of comparisons to activate the proven, accepted and growing dynamic of peer benchmarking as a motivator of behaviour, in this case oriented to energy efficiency improvement. In stimulating stakeholders in energy efficiency, principally food and drink manufacturers, to demand machinery with reduced energy consumption, peer benchmarking would also lever existing engineering design resources within machinery manufacturers and other system stakeholders, rather than leaving all the innovation heavy lifting to be done through specific initiatives and special funding. Behavioural science took the lead at this stage of the system build.

Peer benchmarking requires valid comparability and other aspects of data quality and, most importantly, visibility. Visibility in turn raised the need for secure data sharing and brought into play the benefits which 'Big Data' has brought to other sectors. We then arrived at an 'ecosystem', a self-organising learning community, involving a 'Plan Do Check Act' cycle, as specified in the international energy management standard ISO 50001, but operating at an industry level. The cycle would leverage energy efficiency gains which should be disproportionately greater than would be achievable with machine energy data available only to the respective machine owners or lessees.

Finally, for comprehensive resilience and stability the system needed to be self-sustaining rather than a project limited by funding and time. A means of achieving this based on value to stakeholders and the uniqueness of the system was outlined.

Figure 20 summarises the above sequence of steps in graphical form.

The system now needs to be proved. A consortium has been formed and a feasibility study proposed. This is awaiting funding. Further work could include an extension of the approach to other manufacturing sectors, particularly in process engineering.

Acknowledgements Thanks to Professor Rick Greenough (De Montfort University, UK) for suggesting design guides. Thanks also to the UK Engineering and Physical Sciences Research Council (EPSRC) for their funding under grant reference EP/K030957/1.

\section{Compliance with ethical standards}

Conflict of interest The authors declare that they have no conflict of interest.

Open Access This article is distributed under the terms of the Creative Commons Attribution 4.0 International License (http://creativeco mmons.org/licenses/by/4.0/), which permits unrestricted use, distribution, and reproduction in any medium, provided you give appropriate credit to the original author(s) and the source, provide a link to the Creative Commons license, and indicate if changes were made.

\section{References}

ABB (2009) Power Generation: Energy Efficient Design of Auxiliary Systems in Fossil-Fuel Power Plants. Available from https://libra ry.e.abb.com

Allcott H (2011) Social norms and energy conservation. J Public Econ 95:1082-1095. https://doi.org/10.1016/j.jpubeco.2011.03.003

Altham William (2007) Benchmarking to trigger cleaner production in small businesses: drycleaning case study. J Clean Prod 15:798 813. https://doi.org/10.1016/j.jclepro.2006.07.005

Andersson E, Arfwidsson O, Thollander P (2018) Benchmarking energy performance of industrial small and medium-sized enterprises using an energy efficiency index: results based on an energy audit policy program. J Clean Prod 182:883-895. https://doi. org/10.1016/j.jclepro.2018.02.027

Benedetti M, Bonfa' F, Bertini I, Introna V, Ubertini S (2017) Explorative study on Compressed Air Systems' energy efficiency in production and use: first steps towards the creation of a benchmarking system for large and energy-intensive industrial firms. Appl Energy. https://doi.org/10.1016/j.apenergy.2017.07.100

Boyd Gale A (2005) A method for measuring the efficiency gap between average and best practice energy use: the ENERGY STAR industrial energy performance indicator. J Ind Ecol 9:5165. https://doi.org/10.1162/1088198054821609

Boyd GA (2017) Comparing the statistical distributions of energy efficiency in manufacturing: meta-analysis of 24 Case studies to develop industry-specific energy performance indicators (EPI). Energ Effic 10:217-238. https://doi.org/10.1007/s1205 3-016-9450-y

Brandon A, Ferraro P, List J, Metcalfe R, Price M, Rundhammer F (2017) Do the effects of social nudges persist? Theory and evidence from 38 natural field experiments. https://doi.org/10.3386/ w23277

British Standards Institution (2012) BS EN 16231:2012—energy efficiency benchmarking methodology

British Standards Institution (2014) BS ISO 14955-1:2014: machine tools-environmental evaluation of machine tools part 1: design methodology for energy efficient machine tools

BSI (2012) BS EN ISO 50001:2011—energy management systemsrequirements with guidance for use

BSI (2015) BS ISO 50006:2014—energy management systemsmeasuring energy performance using energy baselines $(\mathrm{EnB})$ and energy performance indicators (EnPI) - general principles and guidance

Cai W, Liu F, Zhang H, Liu P, Tuo J (2017) Development of dynamic energy benchmark for mass production in machining systems for energy management and energy-efficiency improvement. Appl Energy 202:715-725. https://doi.org/10.1016/j.apene rgy.2017.05.180

Cai W, Liu F, Dinolov O, Xie J, Liu P, Tuo J (2018) Energy benchmarking rules in machining systems. Energy 142:258-263. https://doi. org/10.1016/j.energy.2017.10.030

Cambridge Engineered Solutions (2018). Press notice, 29/9/2015. http://cambridge-es.com/press/cambridge-introduces-new-pacli te-conveyor-belt-potato-processing-industry. Accessed 9 May

Chhanwal N, Ezhilarasi PN, Indrani D, Anandharamakrishnan C (2014) Influence of electrical and hybrid heating on bread quality during baking. J Food Sci Technol 52:4467-4474. https ://doi.org/10.1007/s13197-014-1478-4 
Datta AK, Rakesh V (2013) Principles of microwave combination heating. Compr Rev Food Sci Food Saf 12:24-39. https://doi. org/10.1111/j.1541-4337.2012.00211.x

Department for Business, Energy \& Industrial Strategy (2018) Domestic energy consumption in the UK. Energy consumption in the United Kingdom: 2012

Department for Business, Energy \& Industrial Strategy, Food \& Drink Federation, Dairy UK, Scotch Whisky Association, British Beer \& Pub Association, and Maltsters' Association of Great. 2017. Food and Drink: Joint Industry-Government Industrial Decarbonisation and Energy Efficiency Roadmap Action Plan

DNV GL (2018) Veracity-lessons learned. https://developer.verac ity.com/article/lessons-learned-from-more-than-30-pilots. Accessed 14 May

Dolan P, Metcalfe R (2013) Neighbors, knowledge, and nuggets: two natural field experiments on the role of incentives on energy conservation. Centre for Economic Peformance Discussion Papers. https://doi.org/10.2139/ssrn.2589269

Energy Information Administration (2016) International energy outlook 2016. International Energy Outlook, vol 0484. www.eia.gov/ forecasts/ieo/pdf/0484(2016).pdf. 28 June 2017.

Fuchs Lubricants Website (2018) www.fuchs.com. Accessed 9 May

Gontarz AM, Hampl D, Weiss L, Wegener K (2015) Resource consumption monitoring in manufacturing environments. Procedia CIRP 26:264-269. https://doi.org/10.1016/j.procir.2014.07.098

GS1 UK Ltd (2018) GS1 general product classification. https://www. gs1.org/services/gpc-browser. Accessed $18 \mathrm{Jan}$

Gutowski T, Dahmus J, Thiriez A (2006) Electrical energy requirements for manufacturing processes. Energy 2:623-628

Hahn R, Metcalfe R (2016) The impact of behavioral science experiments on energy policy. Econ Energy Environ Policy 5:27-44. https://doi.org/10.5547/2160-5890.5.2.rhah

Hall W, Pesenti J (2017) Growing the artificial intelligence industry in the UK. Available from https://assets.publishing.service.gov. uk/Growing_the_artificial_intelligence_industry_in_the_UK.pdf

Hallsworth M, List JA, Metcalfe RD, Vlaev I (2017) The behavioralist as tax collector: using natural field experiments to enhance tax compliance. J Public Econ 148:14-31. https://doi.org/10.1016/j. jpubeco.2017.02.003

Harman J (2013) The shark's paintbrush. Nicholas Brealey Publishing, Hachette

Hileman MJ, Broadfoot R, Jones RB (2007) System and method for determining equivalency factors for use in comparative performance analysis of industrial facilities. USA

Hwang CL, Yoon K (1981) Methods for multiple attribute decision making. In: Multiple attribute decision making. Lecture Notes in Economics and Mathematical Systems, vol 186. Springer, Berlin. https://doi.org/10.1007/978-3-642-48318-9_3

ICP (2018) Investor confidence project. http://www.eeperformance. org/\#. Accessed $12 \mathrm{Apr}$

Ilevbare IM, Probert D, Phaal R (2013) A review of TRIZ, and its benefits and challenges in practice. Technovation 33:30-37. https ://doi.org/10.1016/j.technovation.2012.11.003

International Standards Organization (2013) Random variables and probability distributions. ISO 20140-1:2013 - automation systems and integration-evaluating energy efficiency and other factors of manufacturing systems that influence the environment. International Standards Organization

International Standards Organization (2017) BS EN ISO/DIS 50001:2017(E): energy management systems-Requirements with guidance for use. Draft for Public Comment 17/3033 7974 DC. ISO

Khatir Z, Taherkhani AR, Paton J, Thompson H, Kapur N, Toropov $\mathrm{V}$ (2015) Energy thermal management in commercial breadbaking using a multi-objective optimisation framework. Appl
Therm Eng 80:141-149. https://doi.org/10.1016/j.appltherma leng.2015.01.042

Kumaraguru S, Rachuri S, Lechevalier D (2014) Faceted classification of manufacturing processes for sustainability performance evaluation. Int J Adv Manuf Technol 75:1309-1320. https://doi. org/10.1007/s00170-014-6184-X

Lightapp (2017) Lightapp website. http://www.lightapp.com. Accessed $14 \mathrm{Feb}$

Maier J (2017) Made smarter-review 2017. Available from https:// www.gov.uk/government/publications/made-smarter-review

Mann D (2007a) The TRIZ route to naturally better system design

Mann D (2007b) Hands-On Systematic Innovation (Technical)

Medeiros da Silva A (2015) Mechatronics design process with energy optimization for industrial machines. Dissertations (2009-). Paper 518. http://epublications.marquette.edu/dissertations_mu/518

Oak Ridge National Laboratory (2008) Customer response to bestpractices training and software tools provided by doe's industrial technologies program (ORNL/CON-502)

OAL Group. Website. https://www.oalgroup.com. Accessed 15 Aug 2017

Oh JS, Binns M, Park S, Kim JK (2016) Improving the energy efficiency of industrial refrigeration systems. Energy 112:826-835. https://doi.org/10.1016/j.energy.2016.06.119

Ökotec Energiemanagement GmbH (2018a) EnPI-Connect in der Praxis-Teil I: Überblick zur Effizienzmethodik

Ökotec Energiemanagement GmbH (2018b) EnPI-Connect in der Praxis-Teil II: Einführungsplan zur Effizienzmethodik

Open Energy Information (2018) Open energy information website. https://openei.org. Accessed 31 Jan

Opower (2018) Opower verification reports. https://www.oracle.com/ industries/utilities/verification-reports/index.html. Accessed 14 Feb

Phylipsen G, Blok K, Worrell E (1998) Handbook on international comparisons of energy efficiency in the manufacturing industry

Phylipsen D, Blok K, Worrell E, De Beer J (2002) Benchmarking the energy efficiency of Dutch industry: an assessment of the expected effect on energy consumption and $\mathrm{CO}_{2}$ emissions. Energy Policy 30:663-679. https://doi.org/10.1016/S0301-4215(02)00023-X

Rappor Metrics Ltd (2018) Rappor metrics website. https://www.rappo rmetrics.com. Accessed $18 \mathrm{Apr}$

Rivas DF, Castro-Hernández E, Perales ALV, van der Meer W (2018) Evaluation method for process intensification alternatives. Chem Eng Process: Process Intensif 123:221-232. https://doi. org/10.1016/j.cep.2017.08.013

TOMRA Website (2018) https://www.tomra.com/en/sorting/food/newsl etter-food-for-thought/2017/opinion-energy-consumption-andefficiency. Accessed 9 May

Toulouse E, Attali S, Bush E, Quack D (2015) Lessons from a decade of efficient product market analysis. In: Proceedings of the 8th international conference on energy efficiency in domestic appliances and lighting, vol 1426

von Esebeck J, Bush E (2018) Household refrigerators and freezers: Recommendations for policy design. Available from www.topte n.eu

WSP Parsons Brinkerhoff, and DNV GL (2015) Industrial decarbonisation \& energy efficiency roadmaps to 2050: food and drink

Yaskawa Website (2018) https://www.yaskawa.com/products/drive s/industrial-ac-drives/general-purpose-drives/u1000-industrial -matrix-drive/-/content/_5d62f215-bd6f-45d0-a382-5c10bf3846 99_Features. Accessed 21 May

Publisher's Note Springer Nature remains neutral with regard to jurisdictional claims in published maps and institutional affiliations. 